\title{
Site-specific Probabilistic Seismic Hazard Map of Himachal Pradesh, India. Part II. Hazard Estimation
}

\author{
Prabhu MUTHUGANEISAN and S.T.G. RAGHUKANTH \\ Department of Civil Engineering, Indian Institute of Technology Madras, \\ Chennai, India; e-mail: raghukanth@iitm.ac.in
}

\begin{abstract}
This article presents site-specific probable seismic hazard of the Himachal Pradesh province, situated in a seismically active region of northwest Himalaya, using the ground motion relations presented in a companion article. Seismic recurrence parameters for all the documented probable sources are established from an updated earthquake catalogue. The contour maps of probable spectral acceleration at $0,0.2$, and $1 \mathrm{~s}(5 \%$ damping) are presented for 475 and 2475 years return periods. Also, the hazard curves and uniform hazard response spectrums are presented for all the important cities in this province. Results indicate that the present codal provision underestimates the seismic hazard at cities of Bilaspur, Shimla, Hamirpur, Chamba, Mandi, and Solan. In addition, regions near Bilaspur and Chamba exhibit higher hazard levels than what is reported in literature.
\end{abstract}

Key words: PSHA, GMPE, seismic hazard, site coefficients, Himalaya.

\section{INTRODUCTION}

The state of Himachal Pradesh, is situated in the north-western part of Himalayas which is seismically very active. The high seismic activity in this region can be attributed to the Himalayan orogeny and to the numerous major

Ownership: Institute of Geophysics, Polish Academy of Sciences;

(C) 2016 Muthuganeisan and Raghukanth. This is an open access article distributed under the Creative Commons Attribution-NonCommercial-NoDerivs license, http://creativecommons.org/licenses/by-nc-nd/3.0/. 
seismic faults present in this region. Some of the major Himalayan faults, such as the Main Frontal Thrust (MFT), Main Central Thrust (MCT), and Main Boundary Thrust (MBT), are present here. As a result, this region has been subjected to several major earthquakes in the past, namely, the Kangra earthquake $\left(M_{w} 7.8,1905\right)$, Uttarkashi earthquake $\left(M_{w} 7,1991\right)$, and Chamoli earthquake $\left(M_{w} 6.8,1999\right)$, which resulted in extensive damages to infrastructure and human life. Hence, this region comes under the Zone IV (severe) and Zone V (very severe) of the seismic zone map of India (IS:1893 2002) with damage intensity of VIII and IX, respectively. Despite the seismicity, the increase in the population in the high seismicity regions of this state has led to increase in the seismic vulnerability (Chandel and Brar 2010). The vulnerability of the local population can be greatly lessened through creating awareness on disaster preparedness and recovery. Some of the aspects of disaster reduction strategies in place for India are discussed in Bansal and Verma (2013). On the other hand, there is an imperative need to assess the seismic hazard of this region as robustly as possible.

The review of earlier seismic hazard studies for this region (Khattri et al. 1984, Bhatia et al. 1999, Parvez et al. 2003, Mahajan et al. 2010, Patil et al. 2014 ) indicates that the previous estimates are based on ground motion relations developed for entirely different geological regions. This issue was addressed by NDMA (2011) which presented ground motion relations for class A sites taking into account the regional geological and seismogenic characteristics of India. However, these ground motion relations proposed cannot be applied to the study region without incorporating the local site effects as shown in the preliminary version of this paper (Prabhu and Raghukanth 2014), using fewer seismic sources and recurrence parameters derived from an already existing catalogue (upto 2009 A.D.) presented by Raghukanth (2011). Therefore, in the companion article (Muthuganeisan and Raghukanth 2016), the regional ground motion relations (GMPE) were developed for the widely prevalent class $\mathrm{C}$ and $\mathrm{D}$ site conditions in the study region.

In this article, the ground motion relations presented in the companion article shall be used to evaluate the site-specific seismic hazard of the study region (between $75^{\circ} 30^{\prime} \mathrm{E}$ to $79^{\circ} \mathrm{E}$ and $30^{\circ} 30^{\prime} \mathrm{N}$ to $33^{\circ} 30^{\prime} \mathrm{N}$ ) at a grid interval of $0.1^{\circ}$. The probabilistic seismic hazard analysis (PSHA) has been carried out by the widely used Cornell-McGuire approach (Cornell 1968, McGuire 1976). Among the 32 seismogenic zones delineated in NDMA (2011), 6 of them are located in a $500 \mathrm{~km}$ radius of the study domain (USNRC 1997) are considered and 301 faults located within these zones, published by GSI (2000), are considered as probable sources. The recurrence parameters are estimated for all the individual faults using a simple heuristic deaggregation approach (Iyengar and Ghosh 2004, NDMA 2011) from a 
homogeneous earthquake catalogue that spans from 270 B.C. to 2013 A.D. prepared by updating the existing catalogue (Raghukanth 2011).

The hazard estimates are presented as contour maps for three ground motion parameters, namely, peak ground acceleration (PGA), short and long period spectral acceleration. These maps are presented for the widely prevalent class C and D sites for two return periods of $475(\sim 500)$ and $2475(\sim 2500)$ years which correspond to 10 and $2 \%$ probability of exceedance in 50 years. In addition, site-specific uniform hazard response spectrum (UHRS) and hazard curves (HC) for some important cities are also presented. These results are necessary to update the design standards for this region and are useful for designers to estimate the expected ground motion at the ground level and for risk assessment.

\section{SEISMO-TECTONIC SETTING OF HIMACHAL PRADESH}

\subsection{Geography}

The state of Himachal Pradesh lies between $30^{\circ} 20^{\prime} \mathrm{N}$ to $33^{\circ} 15^{\prime} \mathrm{N}$ latitudes and $75^{\circ} 45^{\prime} \mathrm{E}$ to $79^{\circ} 00^{\prime} \mathrm{E}$ longitudes, as shown in Fig. 1, and covers an area of $55673 \mathrm{~km}^{2}$. Figure 1 shows the division of this region into two major geological provinces, namely, Indo-Gangetic and Himalayan regions. The district of Una and parts of the districts of Sirmaur, Solan, Bilaspur, Hamirpur and Kangra lie in the Indo-Gangetic plain. The districts of Mandi, Shimla, Chamba, Kullu and parts of the districts of Bilaspur, Hamirpur, Kangra, Sirmaur, and Solan are located in the lower hills of Himalayas while the districts of Kinnaur and Lahaul \& Spiti lie in the outer Himalayas (Karan 1966). The districts of Bilaspur, Hamirpur, Kangra, Mandi, Sirmaur, Solan, and Una generally have brown, alluvial, and grey brown podzolic soils, the districts of Kullu and Shimla have grey-wooded podzolic soils, while Kinnaur, Lahaul \& Spiti, and some parts of Chamba have humus mountain speletal soils (Department of Planning 2003).

The topographic slope variation in the state is from 0.5 to above $70 \%$ (Department of Planning 2003) and the altitude varies from $320 \mathrm{~m}$ (Una District) in the Siwalik range in the south to $6975 \mathrm{~m}$ (Kinnaur District) in the mountainous regions of the greater Himalayas in the north. According to the recent data (Census 2011), the total population of the state is 68.56 million with the current population density of 123 persons per $\mathrm{km}^{2}$. This indicates a growth of $+32.58 \%$ in 20 years (Census 1991). Typical to the Himalayan region, the population in the high altitude region is sparse (only $2 \%$ in Lahaul $\&$ Spiti with $36 \%$ of total area) while it is denser in the lower Himalayan regions. The Kangra district sustains $22 \%$ of the total population in just $10 \%$ of the total area, which is equivalent to the combined population of Una, Hamirpur, and Bilaspur district. Hence, the seismic risk in the Kangra dis- 


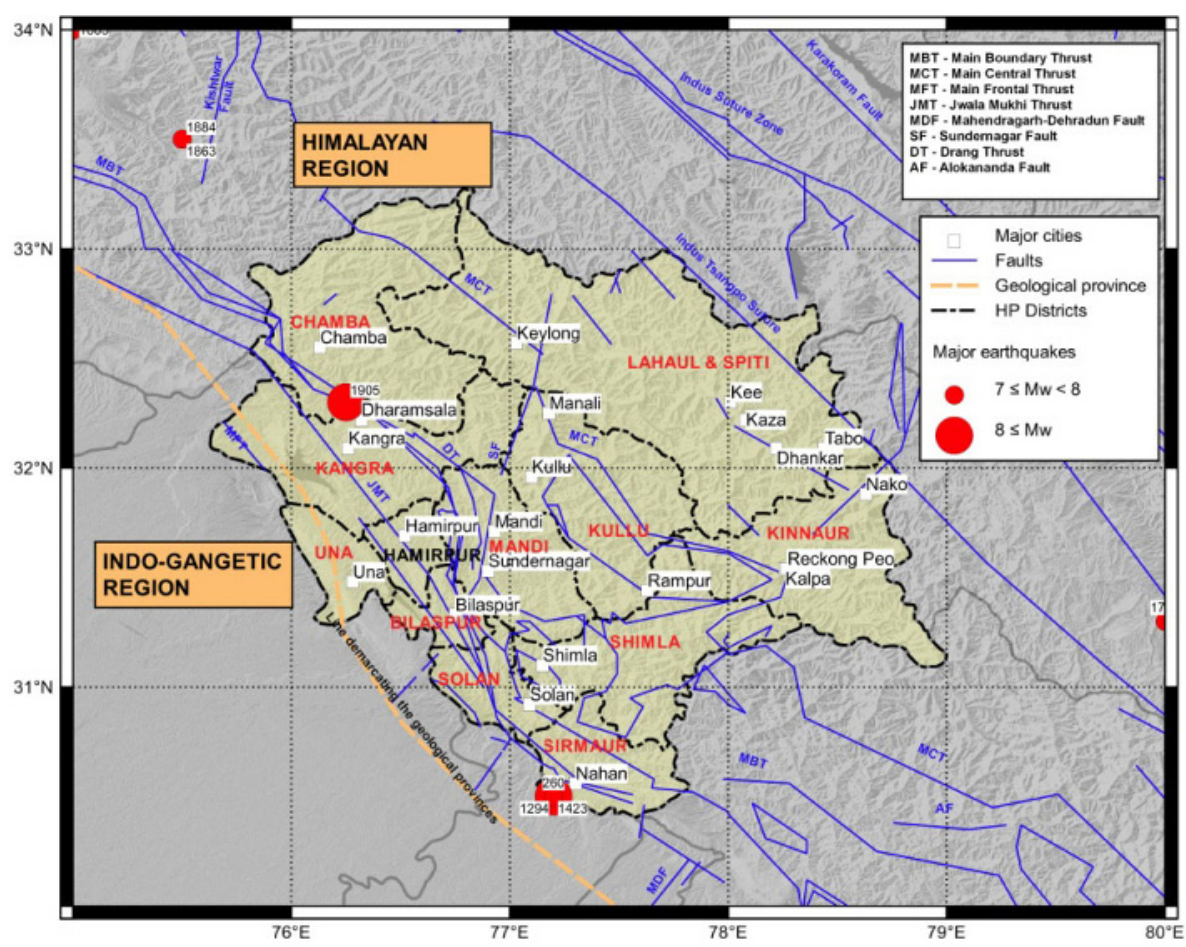

Fig. 1. Fault map of the study region with the location of the test cities shown along with the administrative districts of the state of Himachal Pradesh, India. The demarcation between the two geological divisions, namely the Himalayan and the Indogangetic regions, is shown. The epicentral location of historical great earthquakes of magnitude $M_{w} \geq 7$ and their year of occurrence is marked here. Extreme variability of the altitude, which varies from $320 \mathrm{~m}$ (in Una district) to $6975 \mathrm{~m}$ (in Kinnaur district), can be seen from the terrain map embossed in the background.

trict is only much greater and emphasizes the need to prevent the disastrous consequences of the 1905 Kangra earthquake (Ambraseys and Bilham 2000).

\subsection{Seismotectonics}

The Himalayan orogeny resulted in the formation of a large number of major faults in this region. Thus, the frequent seismic activities observed in this region are due to ruptures at these thrust faults formed by the subduction of the Indian plate below the slow moving Eurasian plate (Valdiya 2002). Some of these prominent faults are the Main Frontal Thrust (MFT) (Valdiya 1976) separating the Indo-Gangetic plain from the Siwalik ranges, the Main Boundary Thrust (MBT) separating the Siwalik ranges from the Lesser Hi- 
malaya, and Main Central Thrust (MCT) separating the Lesser Himalaya from the Greater Himalaya and Tibet. Due to the presence of such large number of faults, some of the major earthquakes have occurred here, such as the Kangra $\left(M_{w} 7.8,1905\right)$, Uttarkashi $\left(M_{w} 7,1991\right)$, Killari $\left(M_{w} 6.2,1993\right)$, and Chamoli $\left(M_{w} 6.8,1999\right)$ earthquakes causing severe damages.

The estimation of the probable ground motion intensity at a site by McGuire-Cornell approach relies on the complete information of the location and seismic activity of all the faults within an effective distance from the site. The faults whose seismic activity can affect Himachal Pradesh have been identified from the Seismotectonic Atlas of India (GSI 2000) and are shown in Fig. 2. NDMA (2011) has delineated these faults into 32 seismogenic zones based on their distribution and known seismicity. The important features of 7 of these zones that are situated within $500 \mathrm{~km}$ from HP state are considered for this study. These zones are the Western Himalaya (SZ-1), Central Himalaya-I (SZ-2), Central Himalaya-II (SZ-3), Altya

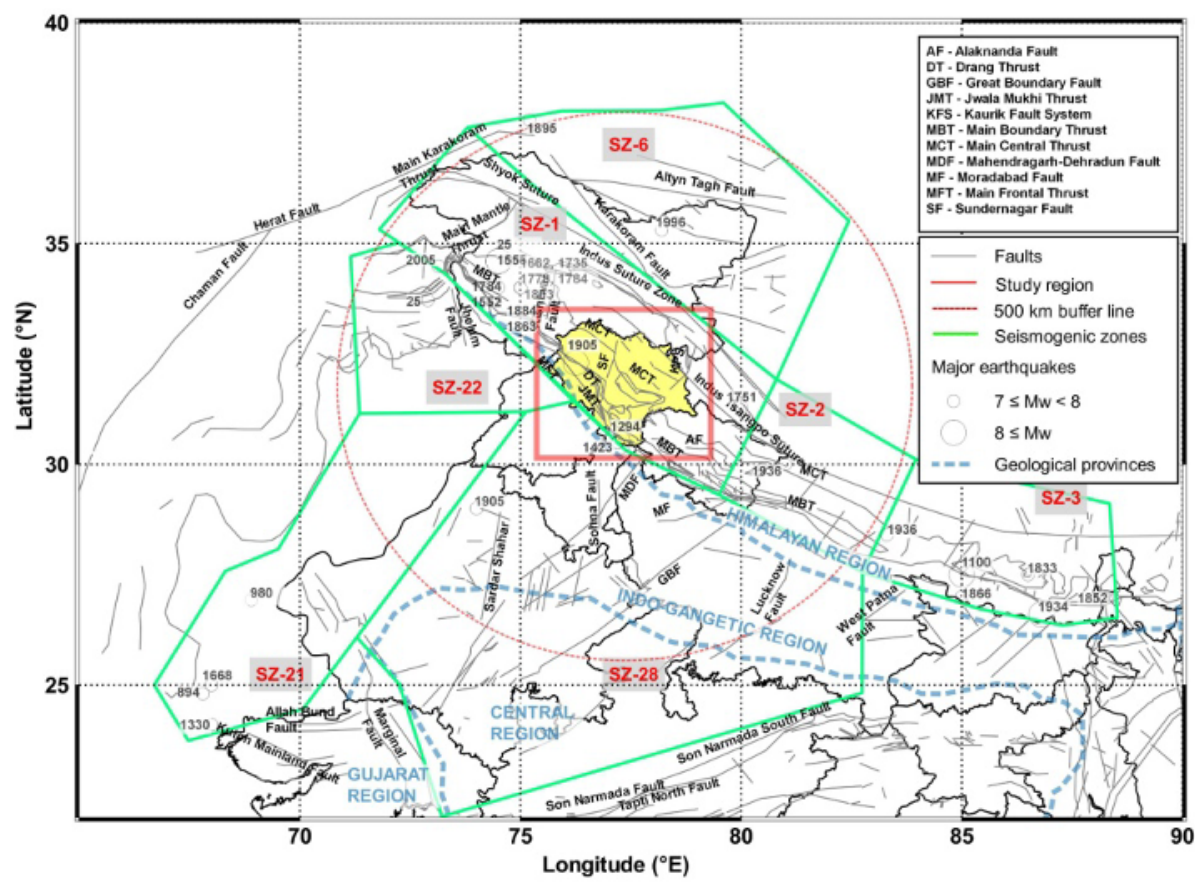

Fig. 2. Faults located in and around Himachal Pradesh and the seismogenic zones from NDMA (2011) considered in this study. A total of 301 fault segments located in seven zones (SZ-1, SZ-2, SZ-3, SZ-6, SZ-21, SZ-22, SZ-28) that control the hazard level of the study region (highlighted in yellow) are considered as probable sources. The epicentres of major seismic events given in Table 1 with magnitude $M_{w} \geq 7$ are indicated here. 
Tegh \& Karakoram (SZ-6), Sindh-Punjab (SZ-21), Upper Punjab (SZ-22), and the Aravali-Bundelkhand (SZ-28) zones and are indicated in Fig. 2.

The HP state lies entirely within the Western Himalaya zone (SZ-1) which is the plate boundary region marked by several prominent tectonic sequences. It can be seen from Fig. 1 that some major faults are situated near important cities. The city of Hamirpur lies on the active Jwala Mukhi Thrust (JMT), which is a neotectonic fault. The MFT, an active neotectonic fault, runs through the south-west of the state and within $10 \mathrm{~km}$ from the city of Una. Drang Thrust (DT), a non-active thrust, runs through the south of the state passing close to the cities of Nahan, Solan, Hamirpur, Mandi, and Dharamshala. The MBT runs to the south of the state passing through the cities of Solan, Mandi, and Dharamsala. The MCT, a non-active thrust, runs through the state through the region between the lower and outer Himalayas bordering the district of Lahaul \& Spiti on the south and runs very close to the cities of Kullu, Manali, Kalpa, and Keylong. This is also referred to as the Zanskar shear zone. The Sundernagar Fault (SF) is a right-lateral shear fault runs through the Sundernagar city.

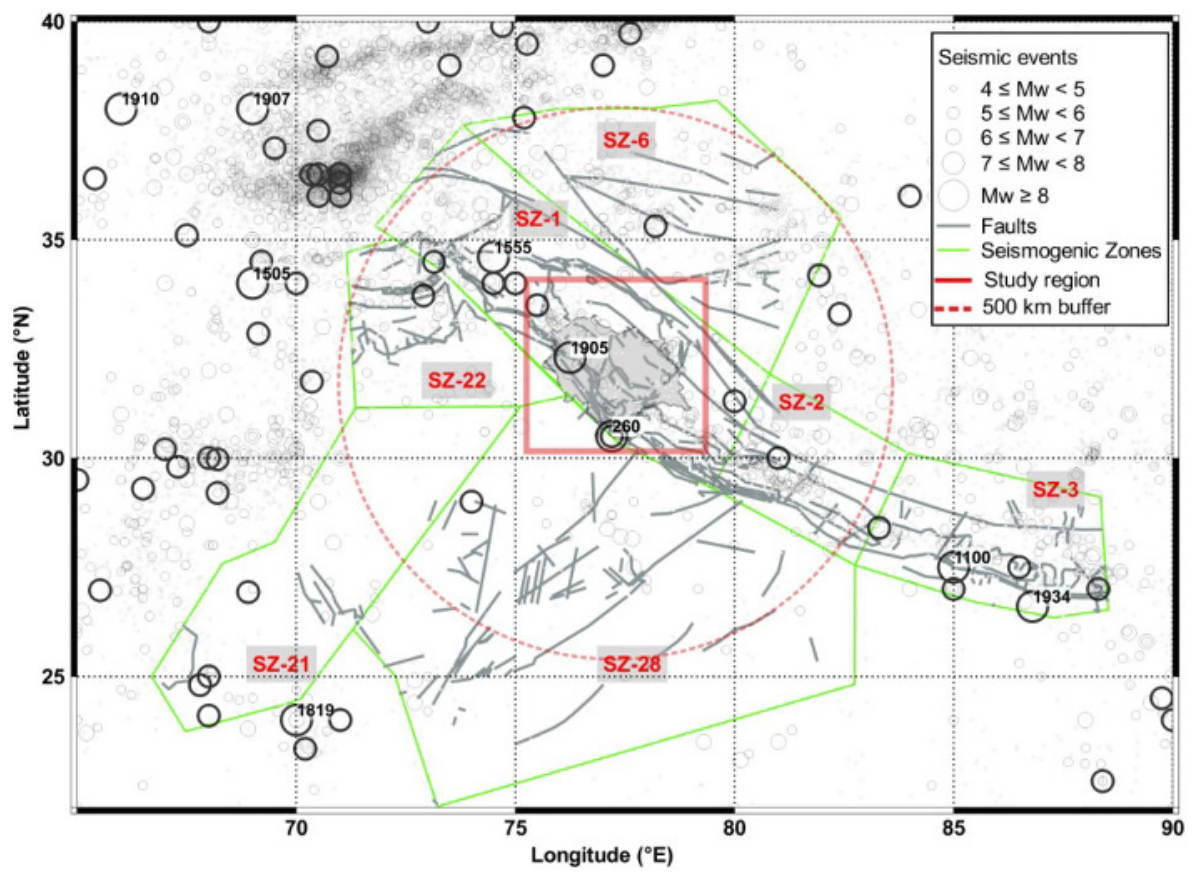

Fig. 3. Declustered seismicity map (from 25 up to 2013 A.D.) observed within the considered seismogenic zones. A total of 3070 independent events are located within the considered seismogenic zones. The major events from the catalogue with magnitude $M_{w} \geq 7$ are marked along with their date of occurrence. 
The source zones SZ-2 and SZ-3 are the continuation of the Himalayan fault sequences comprising of the MBT and MCT along with several transverse faults. It can be seen from Fig. 2 that several large seismic events have been reported in these zones. Zone SZ-6 contains the Karakoram fault and the Altyn Tagh faults. Zones SZ-28 contains several faults such as the Mahendragarh-Dehradun Fault, Moradabad Fault, Sohna Fault, Great Boundary Thrust, and Lucknow Fault. This zone comprises of the Siwalik ranges in the north followed by the alluvial plains of the Indo-Gangetic foredeep. The faults and the seismicity of these considered source zones are shown in Figs. 2 and 3. A total of 301 line fault segments located in these 7 source zones are considered in this study. From Fig. 3, it can be observed that some of the past earthquakes can be associated with existing faults or rupture zones while it is not so straightforward in many cases. In order to carry out PSHA, the seismicity of all the probable sources is characterized in terms of the Gutenberg-Richter (G-R) recurrence relationship using an updated catalogue which will be discussed in the following section.

\section{UPDATED EARTHQUAKE CATALOGUE}

An earthquake catalogue is a collection of the location, time, and magnitude of the past seismicity of a region. A reliable, complete and homogenous catalogue is a prerequisite for deriving the seismicity parameters of the faults within the region. Such a catalogue has been presented by NDMA (2011) (records up to 2008 A.D.) and Raghukanth (2011) (records up to 2009 A.D.) for the source zones used in this study. The above two catalogues are composite and homogeneous comprising of instrumental data, data from historical government archives, and data gathered from paleo-seismic investigations. The most reliable records are the instrumental data obtained from the seismic instrumentation network of Indian Meteorological Department (IMD), International Seismological Centre (ISC), U.S. Geological Survey (USGS), and Pakistan Meteorological Department (PMD). Earlier historical events in these regions have been reported by Oldham (1883), Milne (1911) for the period between 1664 and 1899 A.D., and Quittmeyer and Jacob (1979) for the period between 1914 and 1965 A.D. The data from paleoseismic investigations based on the available geomorphologic evidences helps to identify large magnitude events that have recurrence period of several 100 years.

In this study, the present catalogue (Raghukanth 2011) for these source zones was updated by including the events of magnitude $M_{w} \geq 4$ recorded during the period 2010-2013 A.D. These additional event included in this study are obtained from instrumented data available at the earthquake databases of the International Seismological Centre (ISC). The additional events have been homogenised to a single magnitude scale $M_{w}$ using the magnitude 
conversions adopted by Raghukanth (2011) and NDMA (2011). The large events in the updated catalogue with magnitude $M_{w}$ exceeding 7 within a $500 \mathrm{~km}$ radius from the study region are listed in Table 1 . The earliest event

Table 1

List of earthquakes of magnitude $\geq 7$ within a $500 \mathrm{~km}$ radius of Himachal Pradesh

\begin{tabular}{|c|c|c|c|c|c|}
\hline $\begin{array}{l}\text { Date } \\
\text { (A.D.) }\end{array}$ & Latitude & Longitude & $\begin{array}{c}\text { Magnitude } \\
M_{w}\end{array}$ & $\begin{array}{c}\text { Depth } \\
{[\mathrm{km}]}\end{array}$ & Reference \\
\hline 25 & 33.72 & 72.9 & 7.5 & - & PMD \\
\hline 250 & 34.60 & 74.5 & 8.5 & & Iyengar et al. (1999) \\
\hline 260 & 30.50 & 77.2 & 8 & - & Kumar et al. (2001) \\
\hline 894 & 24.80 & 67.8 & 7.7 & & PMD \\
\hline 980 & 26.93 & 68.9 & 7.6 & & Bilham et al. (2007) \\
\hline 1100 & 27.50 & 85 & 8.5 & & Lave et al. (2005) \\
\hline 1294 & 30.50 & 77.2 & 7.5 & - & Kumar et al. (2001) \\
\hline 1330 & 24.10 & 68 & 7.6 & & Montessus de Ballore (1911) \\
\hline 1423 & 30.50 & 77.2 & 7.5 & - & Kumar et al. (2001) \\
\hline 1552 & 34 & 74.5 & 7.5 & - & IMD \\
\hline 1555 & 34.60 & 74.5 & 8.5 & & Iyengar et al. (1999) \\
\hline 1662 & 34 & 75 & 7.5 & - & IMD \\
\hline 6 May 1668 & 25 & 68 & 7 & & IMD \\
\hline 1735 & 34 & 75 & 7.5 & - & IMD \\
\hline 1751 & 31.30 & 80 & 7 & - & Ambraseys and Jackson (2003) \\
\hline 1778 & 34 & 75 & 7.7 & - & IMD \\
\hline 1784 & 34 & 75 & 7.3 & - & IMD \\
\hline 1803 & 34 & 75 & 7 & - & IMD \\
\hline 26 Aug 1833 & 27.50 & 86.5 & 7.5 & & IMD \\
\hline 1 May 1852 & 27 & 88.3 & 7 & & Oldham (1883) \\
\hline 1 Jan 1863 & 33.50 & 75.5 & 7 & - & IMD \\
\hline 23 May 1866 & 27 & 85 & 7 & & IMD \\
\hline 30 May 1884 & 33.50 & 75.5 & 7.3 & - & IMD \\
\hline 5 Jul 1895 & 37.80 & 75.2 & 7 & & IMD \\
\hline 4 Apr 1905 & 32.30 & 76.25 & 8 & - & IMD \\
\hline 26 Sep 1905 & 29 & 74 & 7.1 & - & IMD \\
\hline 28 Aug 1916 & 30 & 81 & 7.5 & 35 & ISC \\
\hline 15 Jan 1934 & 26.60 & 86.8 & 8.3 & - & IMD \\
\hline 27 May 1936 & 28.40 & 83.3 & 7 & - & IMD \\
\hline 19 Nov 1996 & 35.31 & 78.2 & 7 & - & ISC \\
\hline 8 Oct 2005 & 34.49 & 73.14 & 7.6 & 10 & IMD \\
\hline
\end{tabular}


record for the considered source zones is 25 A.D. reported by PMD (2007) and the largest event magnitude observed was $M_{w} 8.5$. The following section discusses on the declustering of the catalogue and the identification of the completeness intervals.

\subsection{Declustering and completeness check of the catalogue}

As the earthquake occurrences in this PSHA framework are assumed to be Poissonian, the foreshocks and aftershocks present in the updated data have been identified and excluded using the widely adopted declustering approach of Gardner and Knopoff (1974) improved by Uhrhammer (1986). This method identifies event clusters based on a temporal and spatial window. As a result, additional 314 independent events with magnitudes $M_{w}$ ranging from 4-6.9 were added to the database of Raghukanth (2011) for these 7 source zones. The resultant catalogue for these 7 source zones contains a total of 3070 independent events for a period ranging from 25 to 2013 A.D., which comprises of $2554,403,82,25$, and 6 events in the magnitude range of $4 \leq M_{w}<5, \quad 5 \leq M_{w}<6, \quad 6 \leq M_{w}<7, \quad 7 \leq M_{w}<8$, and $M_{w} \geq 8$, respectively. The spatial distribution of these events is shown in Fig. 3.

The temporal distribution of the event magnitudes from the catalogue presented in Fig. 4 highlights two issues with the catalogue. The smaller magnitude events are available only for the last few decades and the larger magnitude events occur at a larger temporal interval, which in most cases extend beyond the catalogue period. Due to the limited availability of data or the lack of it for certain magnitude and temporal intervals, it is necessary to determine the completeness intervals of the present catalogue for different magnitude ranges. These complete parts of the catalogue will give a more re-
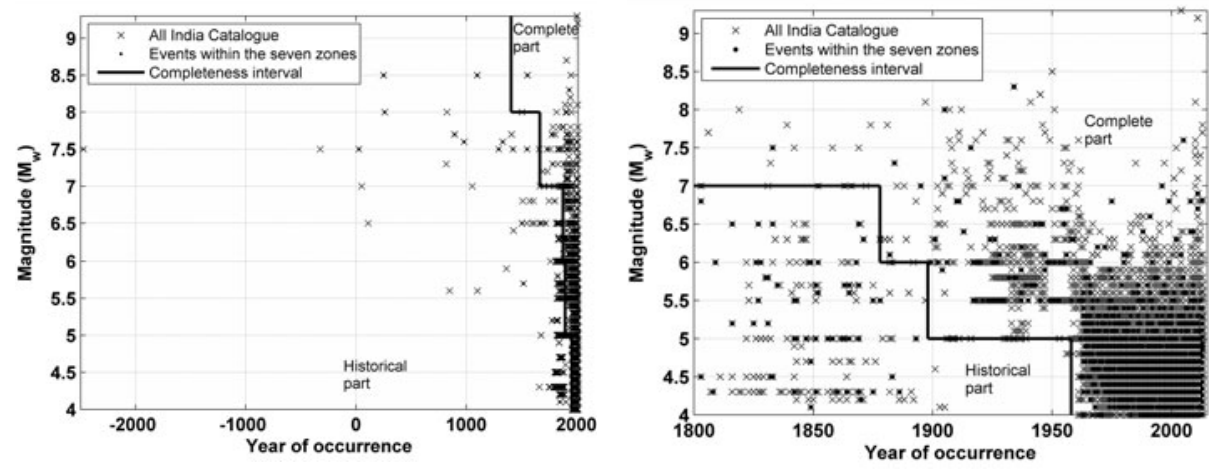

Fig. 4. Temporal distribution of the earthquakes observed within the seven considered seismogenic zones (from 25 up to 2013 A.D.) overlaid on the earthquake catalogue of India (from -2475 B.C. up to 2013 A.D.). The completeness interval obtained by Stepp (1972) approach is also indicated by the solid line. 


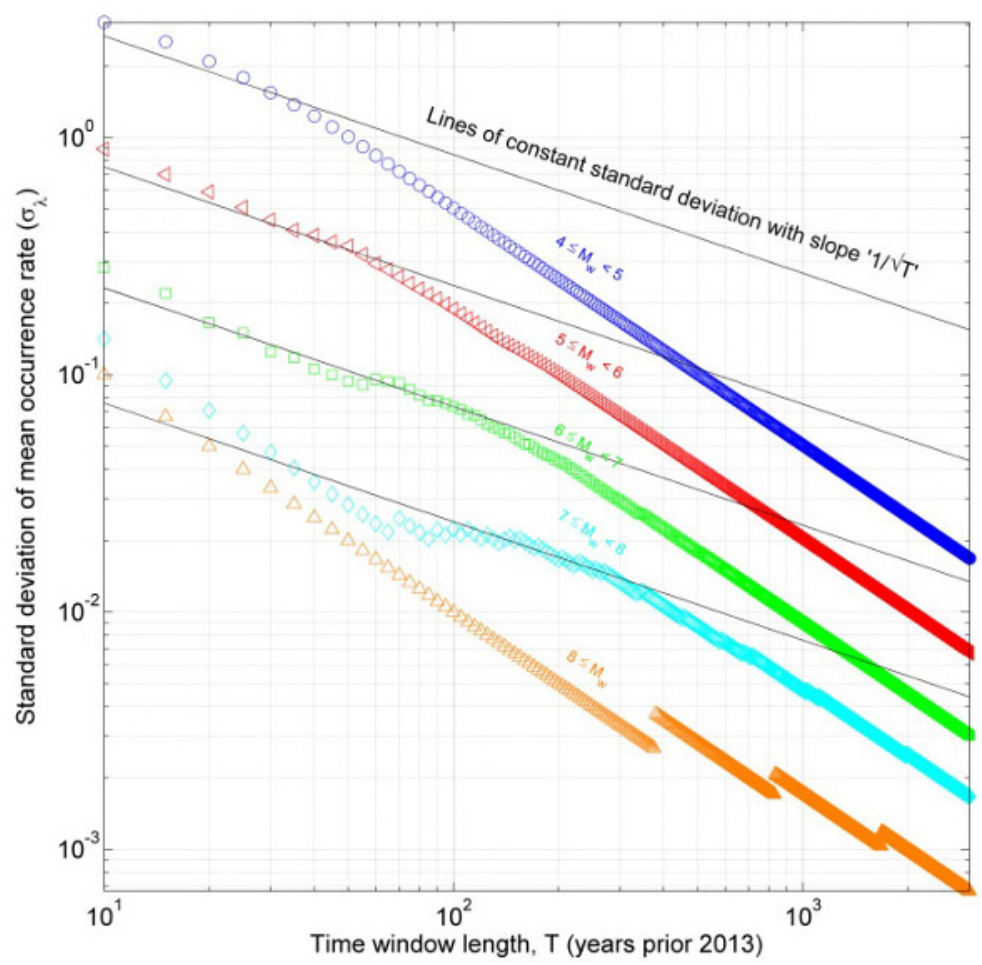

Fig. 5. Completeness test for earthquake data using Stepp (1972) method. Straight lines indicate the theoretical slope of complete data range.

liable estimate of the recurrence parameters. In this study, the widely used completeness test of Stepp (1972) has been used to identify the complete and the incomplete (or historic) part of the catalogue. The complete and the historic part of the catalogue are clearly demarcated and shown in Figs. 4 and 5. In this method, the annual event occurrence rates for several magnitude ranges are estimated for several time windows $(10,20$ years, and so on) that extend backwards in time from the last catalogue period (2013 A.D.). The standard deviation of these mean occurrence rates are plotted as a function of the time window $T$. It can be seen from Fig. 5 that as long as the data is complete these values vary at a constant standard deviation of $1 / \sqrt{T}$ and the completeness interval for each of the magnitude ranges can thus be identified. By this method, the catalogue has been found to be complete in the magnitude ranges of $4 \leq M_{w} \leq 5,5 \leq M_{w} \leq 6,6 \leq M_{w} \leq 7,7 \leq M_{w} \leq 8$, and $M_{w}>8$, for a period of 54 years (1960-2013), 114 years (1900-2013), 134 years (1880-2013), 344 years (1670-2013), and 604 years (1410-2013), respectively. 


\section{RECURRENCE PARAMETERS FOR SEISMIC SOURCES}

In the PSHA framework, the seismic activity of the sources present in the considered seismogenic regions are quantified by means of GutenbergRichter recurrence relations. These relations express the frequency at which these sources can generate seismic events of certain magnitude and their maximum magnitude potential. Thus, if $N(M)$ represents the number of events greater than or equal to a magnitude $M$ recorded during a time period $T$ due to activity at each of the identified seismic sources, then the mean annual rate of exceedance $\lambda_{M}$ of an earthquake of magnitude $M$ at the source can be given as follows

$$
\log _{10}\left(\lambda_{M}\right)=a-b M,
$$

where $a$ is the logarithmic value of the mean annual value of $N\left(M>M_{0}\right)$; where $M_{0}$ is the smallest significant magnitude that had occurred at the seismic source; and $b$ indicates the activity rate of the seismic sources and their potential to produce larger or smaller earthquakes. In this study, the value of $M_{0}$ is taken to be 4 as the occurrence of earthquakes of magnitudes $M_{w}<4$ are not significant from design considerations and are usually not strong enough to cause significant structural damages. Knopoff and Kagan (1977) noted that the above recurrence relation needs to have an upper bound to reflect the fault potential realistically but this information cannot be obtained precisely from the catalogue due to the uncertain nature of future events.

In order to estimate the bounded $\mathrm{G}-\mathrm{R}$ recurrence parameters $(a, b$, and $\left.M_{\max }\right)$, complete information on the seismicity of all the individual faults is necessary, but not always available for all the faults. Hence, it is common to estimate these parameters for the source zones and assign it to all the faults located within the source zones resulting in a conservative and higher hazard estimate. A viable alternative method is to estimate the recurrence parameters for the source zones and deaggregate it to fault level recurrences based on available fault specific information such as fault length and fault seismicity (Iyengar and Ghosh 2004, NDMA 2011). In this study, the latter method has been adopted and the zonal values of $a, b$, and $M_{\max }$ for all the 7 considered seismic source zones have been estimated from the updated catalogue using the Kijko and Graham (1998) and Kijko (2004) method. This statistical procedure takes into account the uncertainty in the catalogue information and incompleteness of the catalogue data. In this procedure, the updated catalogue is partitioned into a complete part and an extreme part based on the completeness interval determined using the Stepp (1972) method discussed earlier. The magnitude uncertainty is taken as 0.5 and 0.3 for the incomplete and complete part respectively (NDMA 2011). 
Updated seismicity parameters

for the seven seismogenic zones in Himachal Pradesh

\begin{tabular}{|l|l|c|c|c|c|c|}
\hline $\begin{array}{c}\text { Source } \\
\text { no. }\end{array}$ & \multicolumn{1}{|c|}{ Zones } & $b$ value & $\mathrm{N}(4)$ & $\begin{array}{c}\text { Max. } \\
\text { potential } \\
\text { magnitude } \\
M_{\max }\end{array}$ & $\begin{array}{c}\text { Number } \\
\text { of } \\
\text { earthquakes }\end{array}$ & $\begin{array}{c}\text { Number } \\
\text { of } \\
\text { faults }\end{array}$ \\
\hline SZ-1 & Western Himalaya & $0.81 \pm 0.02$ & 3.70 & 8.8 & 1025 & 97 \\
SZ-2 & Central Himalaya -I & $0.67 \pm 0.04$ & 2.80 & 7.8 & 353 & 27 \\
SZ-3 & Central Himalaya-II & $0.70 \pm 0.04$ & 1.80 & 8.8 & 382 & 39 \\
SZ-6 & Altya Tegh \& Karakoram & $0.82 \pm 0.03$ & 4.50 & 7.3 & 827 & 31 \\
SZ-21 & Sindh-Punjab & $0.71 \pm 0.06$ & 0.58 & 8.0 & 102 & 11 \\
SZ-22 & Upper Punjab & $0.95 \pm 0.05$ & 1.95 & 8.0 & 255 & 27 \\
SZ-28 & Aravali-Bundelkhand & $0.75 \pm 0.06$ & 0.80 & 7.0 & 126 & 68 \\
\hline
\end{tabular}

The estimated zonal seismicity parameters and the total number of faults present in all the 7 seismogenic zones considered in the study are listed in Table 2. It can be seen that all of these zones have a maximum magnitude potential of $M_{w} \geq 7$ and 3 of these zones have $N(4)>2$ which means that they produce, on an average, 2 events of $M_{w} \geq 4$ every year. The SZ-1, which encompasses the study region, has the largest number of faults and experiences the largest number of earthquakes. The source zone pairs that exhibit similar seismic activity levels are SZ-1 and SZ-6, SZ-2 and SZ-3, SZ-21 and SZ-28. These updated source zone recurrence parameters are compared with the previously reported NDMA (2011) values, as shown in Fig. 6. It can be seen that there is only a slight variation in these values and

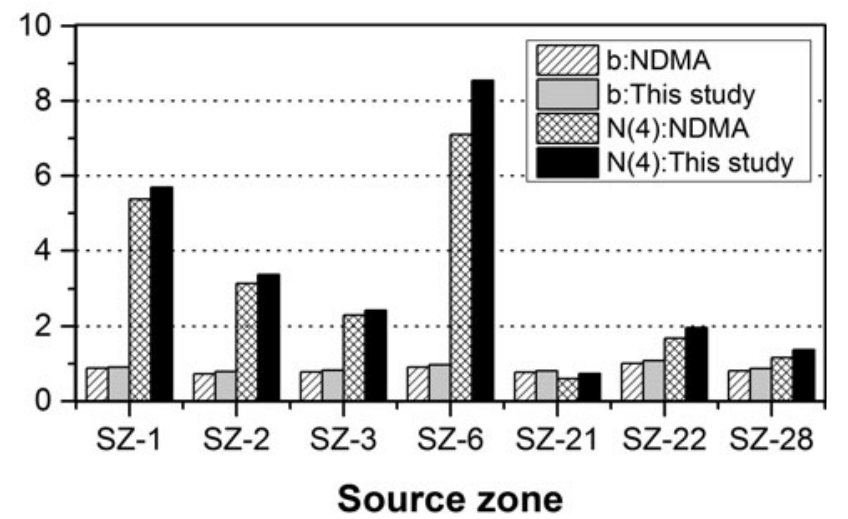

Fig. 6. Comparison of the updated source zone recurrence parameters with the NDMA (2011) values. 


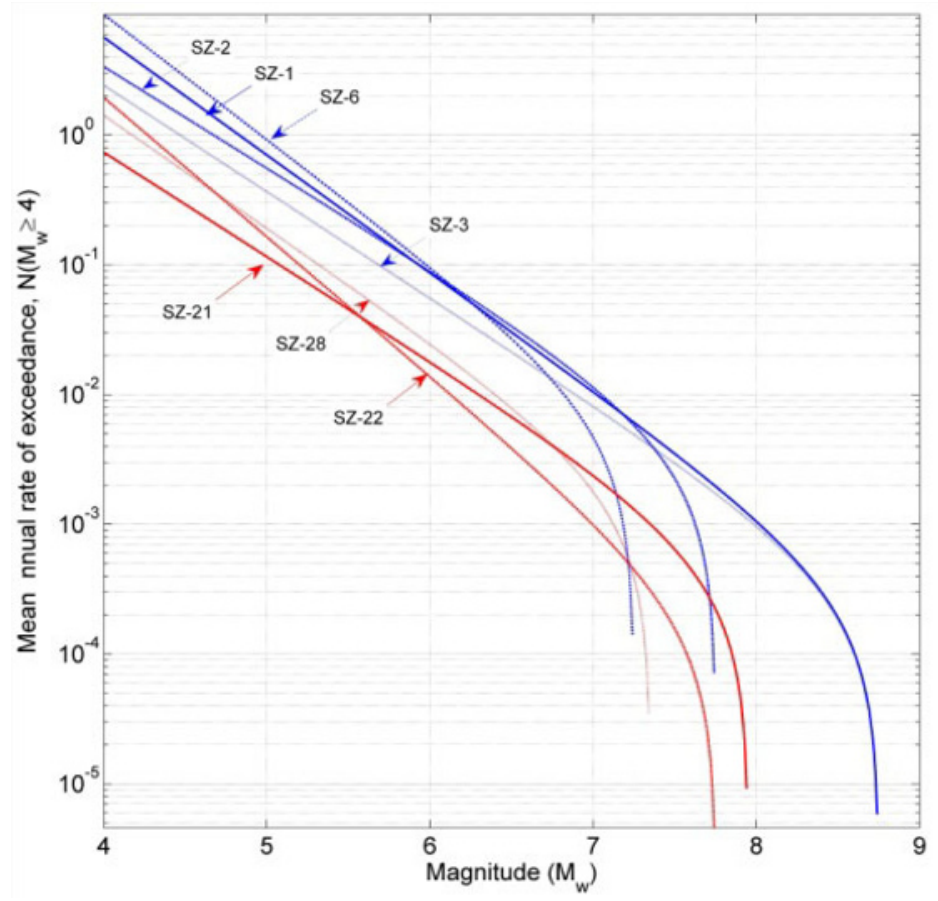

Fig. 7. Bounded Gutenberg-Richter magnitude-frequency relationship for the seven seismogenic zones. $N$ indicates the mean annual occurrence of $M_{w} \geq 4$ events.

the additional data has contributed to reducing the uncertainty in the $b$-value marginally. Since there had not been any major event in this region, the $M_{\max }$ values remain unchanged. Thus, the uncertainty in the parameters for a particular seismogenic region reduces when the catalogue becomes more complete for that region. The bounded G-R recurrence curve by plotting $\log \left(\lambda_{M}\right)$ against magnitude $M_{w}$ for all the seismic source zones considered in this study is shown in Fig. 7.

\subsection{Fault deaggregation}

Since the faults within the same zone exhibit varying levels of seismicity, it may be even more appropriate to consider the fault level recurrences. However, the gaps in the existing catalogue and lack of information on the slip characteristics of the faults make it difficult to achieve a clear consensus on the rupture potential of all the identified faults. Hence, the heuristic approach of Iyengar and Ghosh (2004) is used in this study. In this method, the total seismicity within a zone is conserved while estimating the $a$ value of all the faults. These fault specific $a$ values are estimated by taking into considera- 

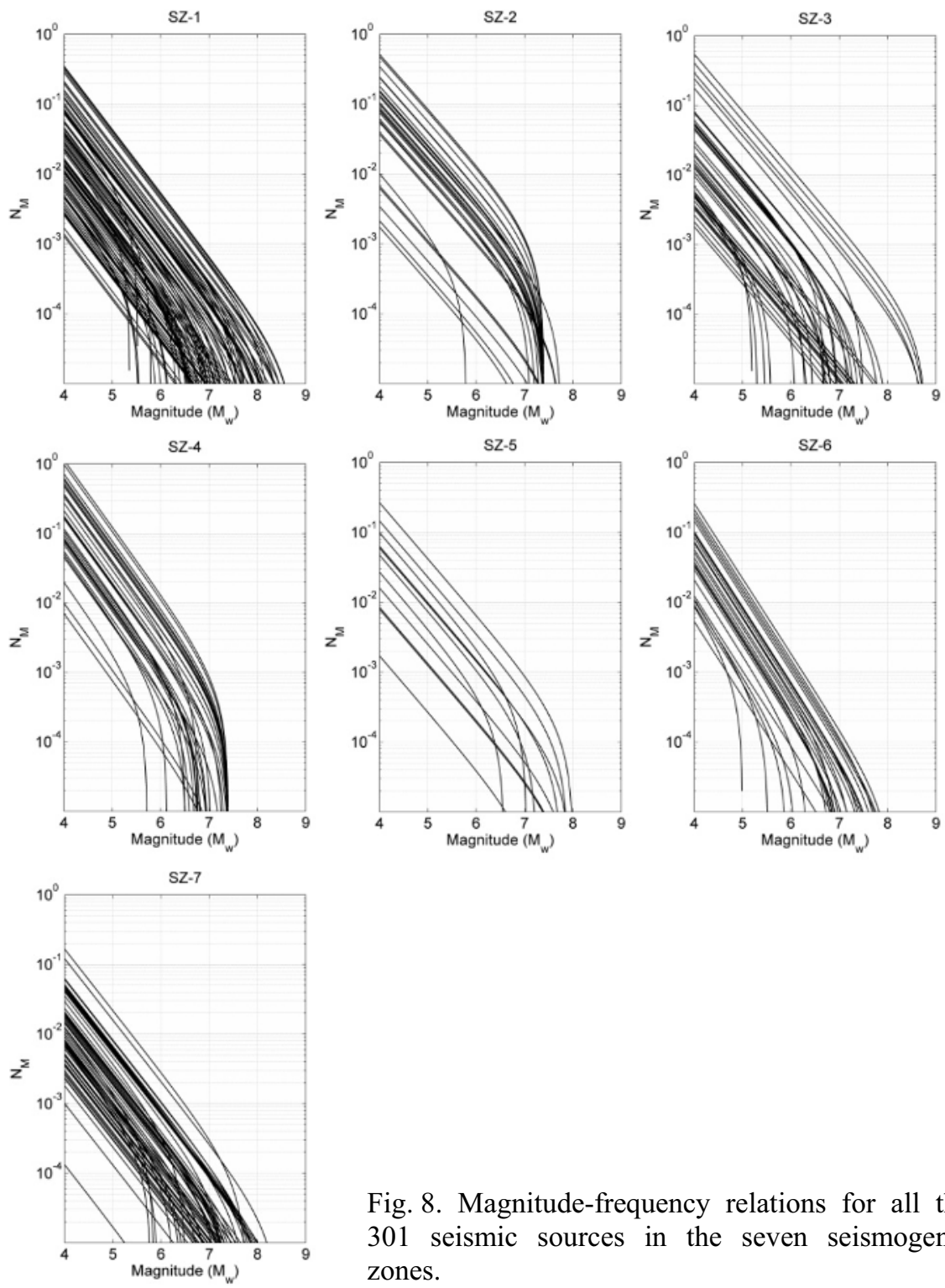

Fig. 8. Magnitude-frequency relations for all the 301 seismic sources in the seven seismogenic zones.

tion the potential of a fault to rupture and known activity. In this study, the background seismicity within a source zone is also taken into consideration by associating these events with the nearest faults in the zone. Thus, the value of $a$ of $i$-th fault is taken as the zonal $a$ value proportioned by a factor determined by fault length ratio and fault activity ratio. Thus, $a_{i}$ will be 


$$
a_{i}=N_{i}\left(m_{0}\right)=0.5\left(\frac{L_{i}}{L_{z}}+\frac{n_{i}}{N_{z}}\right) N\left(m_{0}\right),
$$

where the fault length ratio is the ratio of the fault length of the $i$-th fault $L_{i}$ to the sum of the fault lengths of all the zonal faults $\left(L_{z}=\sum_{i=1}^{N s} L_{i}\right)$. The fault activity ratio is the ratio of the event occurrences at the fault $n_{i}$ to total events in the zone $N_{z} . N_{s}$ is the number of faults present in a zone and $N\left(m_{0}\right)$ is the total number of annual events of magnitude greater than 4 due to all sources within a zone. Since, it is difficult to ascertain the magnitude versus rupture potential of individual faults due to the uncertainties in the fault activity, the $b$ value of all the faults within a zone is assumed to be same as the zonal $b$ value. The value of $M_{\max }$ for all the faults in each zone are taken as the maximum magnitude of past events associated with the fault plus 0.5 units, in order to account for uncertainty in the past data. For faults lacking past event records, Wells and Coppersmith (1994) relation has been used to evaluate $M_{\max }$ based on rupture length. Furthermore, the $M_{\max }$ values for individual faults are constrained by the zonal $M_{\max }$ values. These fault level recurrence parameters are estimated for all the 301 faults identified in the 7 seismogenic zones considered in this study. The fault level recurrence relations obtained from the above procedure are shown in Fig. 8. These values define the seismicity of all these causative faults while performing the PSHA.

\section{PROBABILISTIC SEISMIC HAZARD ANALYSIS (PSHA)}

The estimation of the seismic forces, which are expected to act on a structure during its design life, in a deterministic manner, can be unreliable due to the various uncertainties involved in the source and site characteristics. In order to address this problem, Cornell (1968) introduced the concept of PSHA to estimate the seismic hazard level (in terms of a ground motion intensity measure) at a site by taking into account the uncertainties associated with the probable sources, seismicity and the source-to-site path. Der Kiureghian and Ang (1977), in order to include a finite source and its uncertainty, later improved Cornell's assumption of point-source model to characterize sources. Addressing the uncertainties, which are broadly classified into aleatory and epistemic uncertainties, is the main idea behind PSHA. In this methodology, the aleatory uncertainty is addressed by the usage of probability distributions of the source to site distance, magnitude and the ground motion relations. The PSHA estimations become more reliable as the uncertainties reduce as more data becomes available on seismicity, rupture characteristics, etc., in the future. 
The methodology of PSHA implemented for this study is widely discussed in the available literatures (Kramer 1996, NDMA 2011). Here, the hazard level estimations are simplified by making an assumption that these seismic events recorded on a fault are independent and hence can be assumed as a stationary Poisson process. This simplifies the computation of probability of exceedance of the monitored intensity level (can be PGA, for example) in a time frame of next $T$ years and can be expressed as

$$
P\left(Y>y^{*} \text { in } T \text { years }\right)=1-e^{-\mu_{y} T} .
$$

Here, $\mu_{y *}$ indicates the mean annual rate of exceedance of the ground motion measure $y^{*}$ (and its reciprocal is the average return period $T_{r}$ of the event capable of producing $y^{*}$ ). If there were $K$ number of probable sources or faults in the region, then $\mu_{y *}$ can be computed as

$$
\mu_{y^{*}}=\sum_{i=1}^{K} N_{i}\left(m_{0}\right) \times \int_{m=m_{0}}^{m_{u}} \int_{r=r_{\min }}^{r_{\max }} P\left[Y>y^{*} \mid m, r\right] p_{R \mid M}(r \mid m) p_{M}(m) d r d m .
$$

where $m_{0}$ and $m_{u}$ indicate the minimum and the maximum threshold magnitude observed at the fault; $r_{\min }$ and $r_{\max }$ are the minimum and maximum site distances from the fault; $p_{M}(m)$ is the probability density function of the exponentially distributed magnitude which can be obtained through the G-R relationship; $p_{R \mid M}(r \mid m)$ is the conditional probability density function of hypocentral distance which can be obtained numerically for the identified probable sources; $P\left[Y>y^{*} \mid m, r\right]$ denotes the conditional probability that the chosen ground motion intensity level is exceeded for a given magnitude and distance which can be determined using the ground motion relationship. As discussed earlier, this value is obtained as a lognormal random variable with the mean value given by the attenuation equation and the standard deviation given by the error term $\ln (\varepsilon)$. All the causative faults within a radius of $500 \mathrm{~km}$ have been considered in accordance with the international guidelines (USNRC 1997) for estimating the seismic hazard at a site. The seismicity characteristics of each of these sources are expressed in terms of fault-level recurrence parameters. Finally, with the regional site-specific ground motion models presented in the companion paper (Muthuganeisan and Raghukanth (2016), the seismic hazard levels of the state of Himachal Pradesh can be estimated.

\section{SEISMIC HAZARD OF HIMACHAL PRADESH}

In this study, the seismic hazard of the state of Himachal Pradesh has been evaluated at a $0.1^{\circ}$ grid interval covering the region between the longitudes $75^{\circ} 30^{\prime} \mathrm{E}$ to $79^{\circ} \mathrm{E}$ and the latitudes $30^{\circ} 30^{\prime} \mathrm{N}$ to $33^{\circ} 30^{\prime} \mathrm{N}$. Even though separate ground motion models are presented for class $\mathrm{C}$ and $\mathrm{D}$ conditions, it is not possible to identify the exact spatial distribution of the soil conditions 
throughout the state. Hence, this study presents two sets of hazard maps for both class $\mathrm{C}$ and $\mathrm{D}$ site conditions in terms of the three ground motion parameters, namely, PGA, $S a(0.2 s)$ and $S a(1.0 s)$. Thus, for any site located within the study region, the uniform hazard response spectrums can be constructed, by IBC (2009) approach, by picking the values from the hazard map of that specific site class. In addition to the hazard maps, the seismic hazard curves for PGA values for both the site classes are presented for the 12 district-headquarters of Himachal Pradesh and are shown in Fig. 9. It can be seen that Una, being the only test site in the Indo-Gangetic region, experiences lower hazard values than the other cities.

As hazard estimation considering the regional geology and local site characteristics has not been reported by the previous studies for this region, a
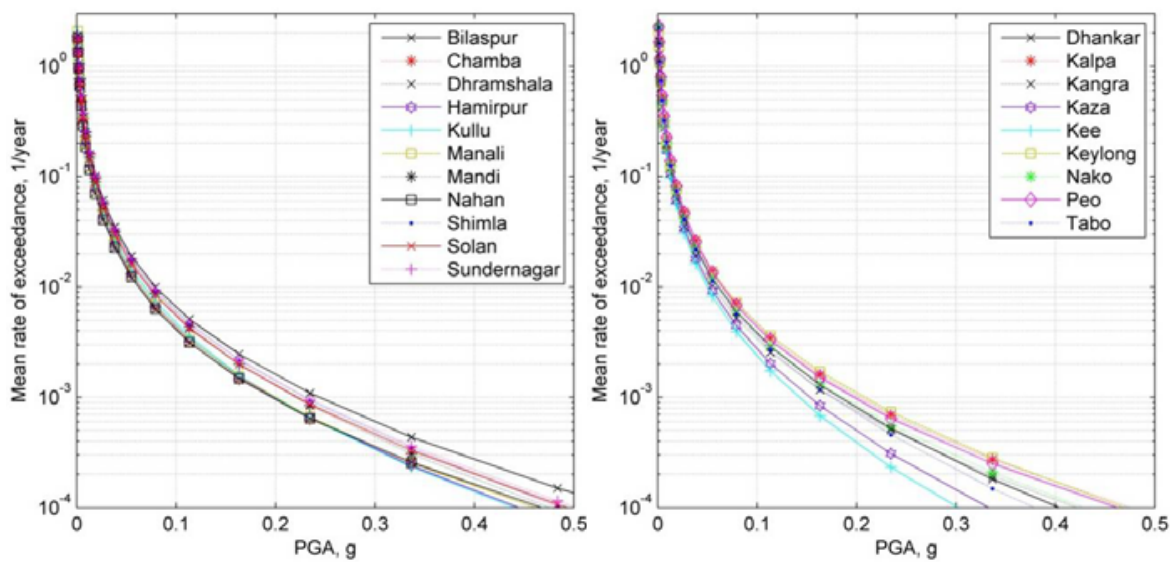

Fig. 9a. Seismic hazard curves for class $\mathrm{C}$ sites in some important cities.

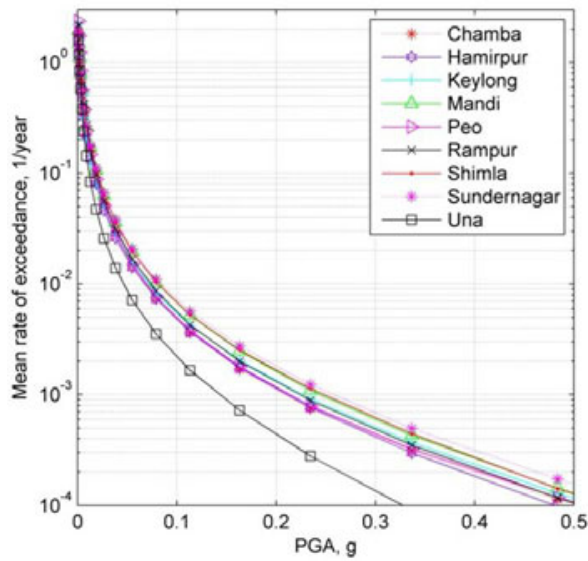

Fig. 9b. Seismic hazard curves for class D sites in some important cities. 
reasonable comparison cannot be made. However, it is generally observed that the site effects play an important role in seismic hazard estimation. For the return period of 475 years, the estimated PGA values for class C and D sites reported in this study are in the ranges of $0.04-0.2$ and $0.04-0.21 \mathrm{~g}$, respectively. Due to the site amplification effects, the values reported in this study are found to be higher in comparison with the values reported by NDMA (2011) for the same return period, whose PGA values presented for class A sites range from 0.05-0.12 g. Similarly, these values are higher than those reported by Parvez et al. (2003), obtained by a deterministic approach (design ground acceleration ranges from 0.08-0.15 g). When compared with the case 1 (varying $b$ value) estimates of Patil et al. (2014) that range between $0.078-0.15 \mathrm{~g}$, it can be seen that their values underestimates the hazard in this region. When compared with their case 2 (constant $b$ value), the hazard is in the range of 0.12-0.26 g which shows higher estimates for the region except for the Bilaspur and Chamba region. Hence, consideration of the fault level seismicity is found to map the seismic hazard more realistically.

The seismic zoning map of India (IS:1893 2002) designates the entire central part of HP as Zone V (very severe) and the peripheral regions are designated as Zone IV (severe) with zero period acceleration values as 0.36 and $0.24 \mathrm{~g}$, respectively, for maximum considered earthquake (MCE) scenario. On comparison with the PGA values at class D sites with 2475 year return period, it can be seen that values estimated are in the ranges of 0.230.38 and $0.18-0.38 \mathrm{~g}$ for the regions designated as Zone V and Zone IV, respectively. The annex E of the IS:1893 (2002) provides the ZPA for Shimla as $0.24 \mathrm{~g}$ (for MCE) whereas the predicted value from this study is around $0.35 \mathrm{~g}$ (for 2475 years return period). Similarly, the hazard levels are underestimated for the cities of Chamba, Nahan Solan, Bilaspur, and Shimla which are depicted as Zone IV. On the other hand, the PGA values of the regions depicted as Zone V in the Indian code (IS:1893 2002) are found to be lower than the values reported by the Indian code.

Similarly, the seismic hazard curves can also be built for other spectral acceleration values, apart from PGA, for period ranging from 0.01 to $4 \mathrm{~s}$ using the corresponding attenuation coefficients given in Tables 3 to 6 of the companion paper (Muthuganeisan and Raghukanth 2016). Using these curves, it is possible to extract the response spectrums for design basis earthquake and maximum considered earthquake which correspond to 10 and $2 \%$ probability of exceedance during the design life of 50 years (IBC 2009). The resulting response spectra are known as uniform hazard response spectrum (UHRS) due to the assumption of uniform probability of exceedance throughout the frequency ranges. The UHRS curves for class $\mathrm{C}$ and $\mathrm{D}$ sites 

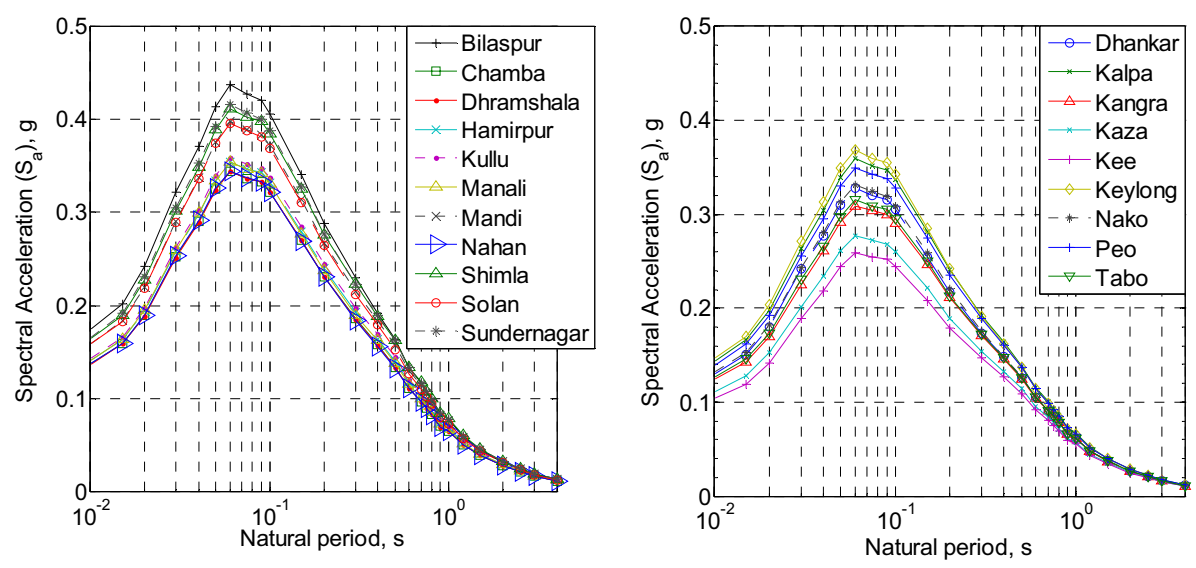

Fig. 10a. UHRS curve for class C sites in some important cities (return period: 475 years).

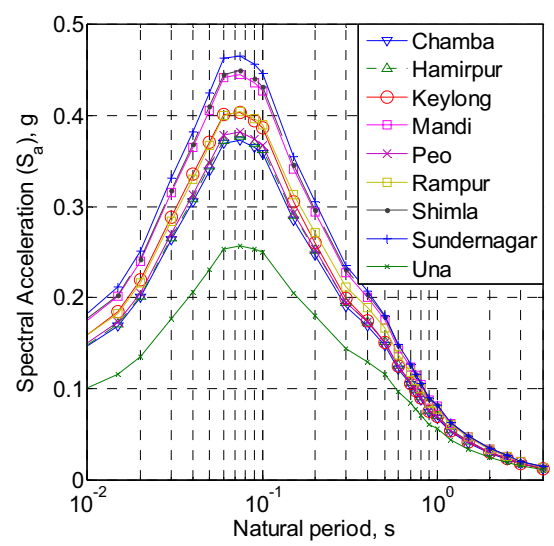

Fig. 10b. UHRS for class D sites in some important cities (return period: 475 years).

of some important cities in HP are shown in Figs. 10 to 11 for two return periods of 475 and 2475 years, respectively.

It is well known that characterization of ground motion in terms of peak measures such as the PGA may be sufficient for analyzing simple regular structures by equivalent static analysis method. However, for structures that are tall or irregular and exhibit complex behavior, it becomes necessary to conduct a dynamic analysis and the same has been recommended by design codes (IS:1893 2002, IBC 2009). Hence, in this work, the contour plots of short period $S a(0.2 s)$ and long period $S a(1.0 s)$ spectral accelerations have been also been estimated. The NDMA (2011) report has already published the contour maps of these three parameters for class A sites. It has been 

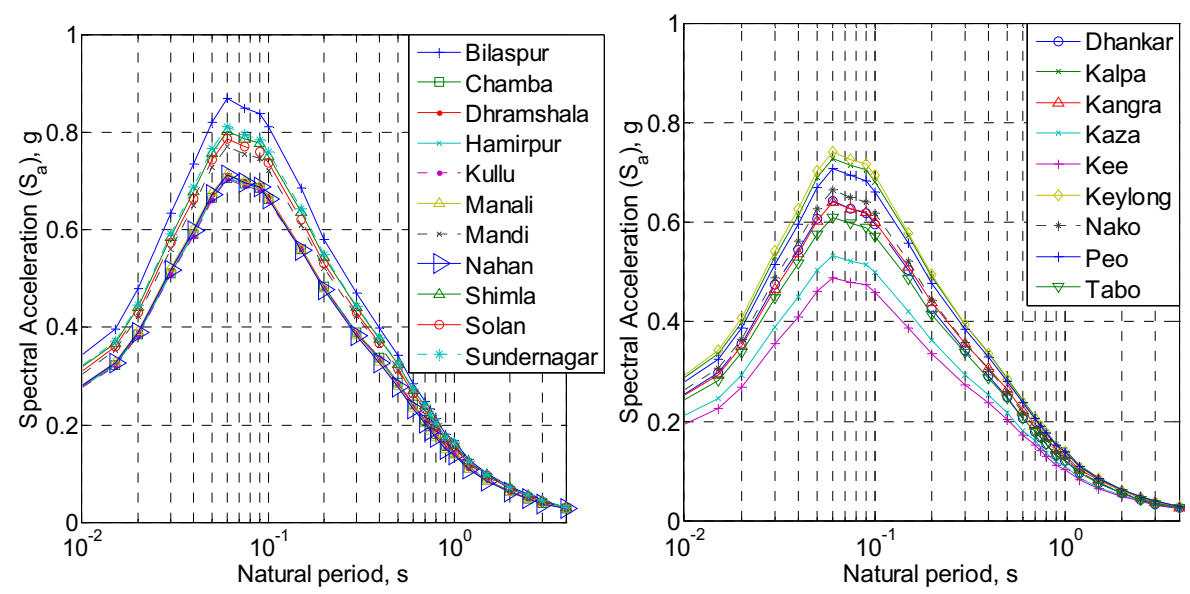

Fig. 11a. UHRS curve for class C sites in some important cities (return period: 2475 years).

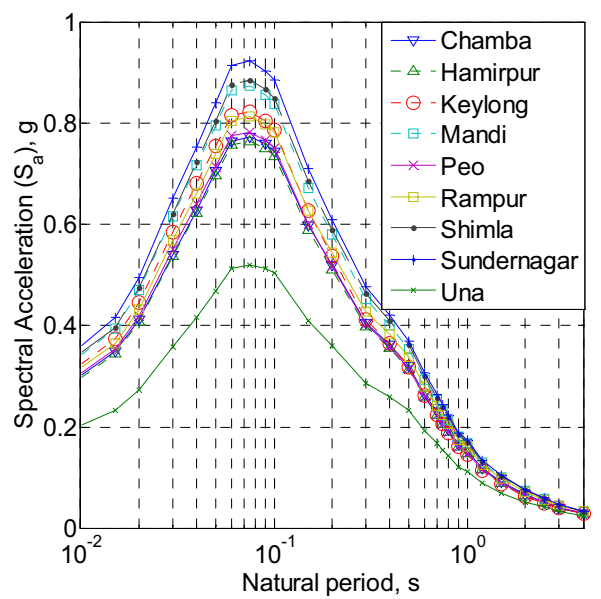

Fig. 11b. UHRS for class D sites in some important cities (return period: 2475 years).

shown earlier that the test sites were primarily of classes C and D with few exceptions. Since the determination of the site conditions throughout the region is not a feasible exercise, it becomes reasonable to provide these contour plots for both the class C (Figs. 12 to 17) and class D site conditions (Figs. 18 to 23 ).

The spatial variation of peak ground acceleration (PGA), the short period spectral acceleration $S a(0.2 s)$ and the long period spectral acceleration $S a(1.0 \mathrm{~s})$ for the two return periods of 475 and 2475 years can be observed from these contour plots. It can be observed that the hazard values in the 


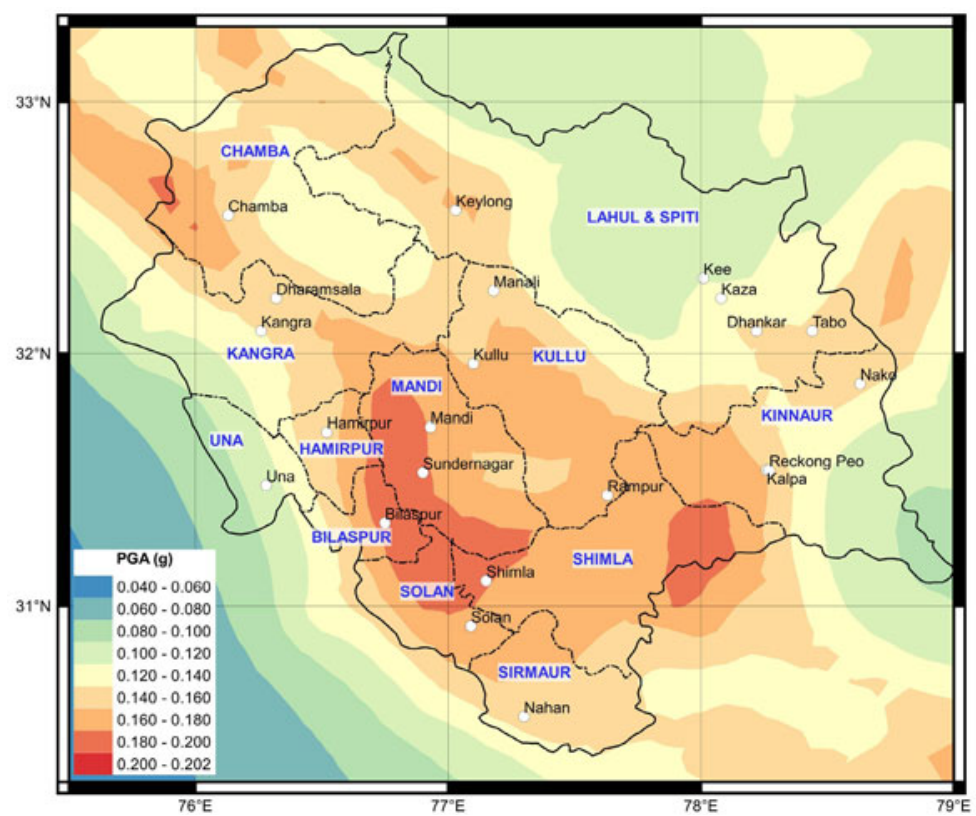

Fig. 12. PGA contours with a return period of 475 years for $\mathrm{C}$ type sites.

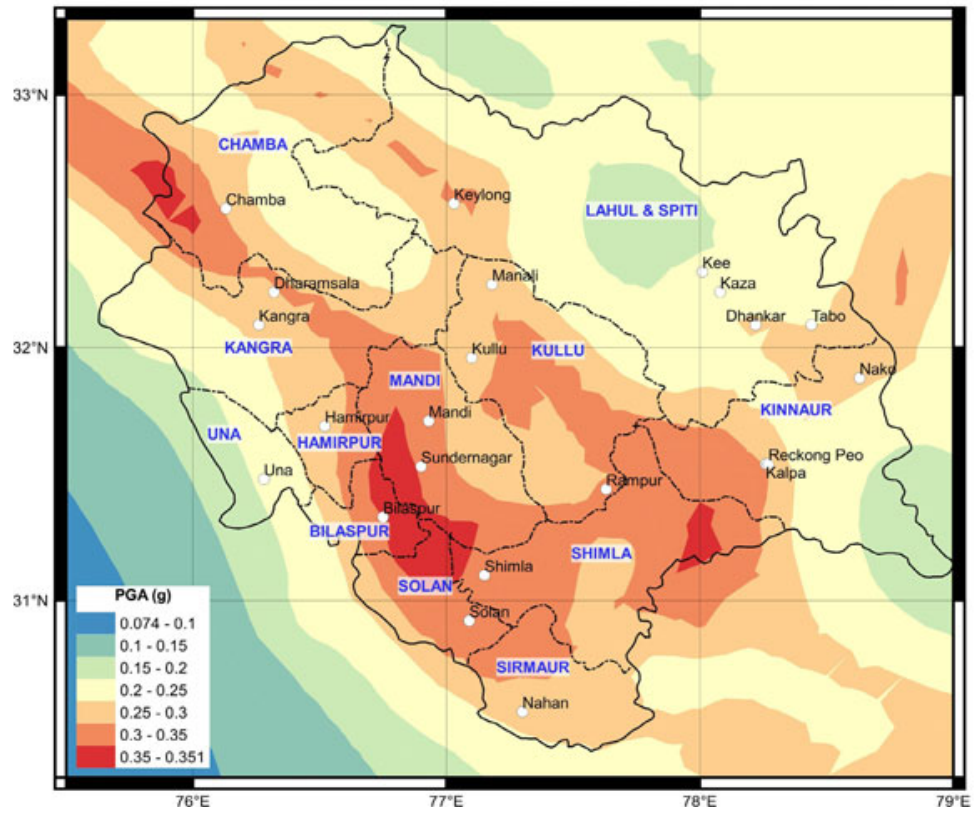

Fig. 13. PGA contours with a return period of 2475 years for $C$ type sites. 


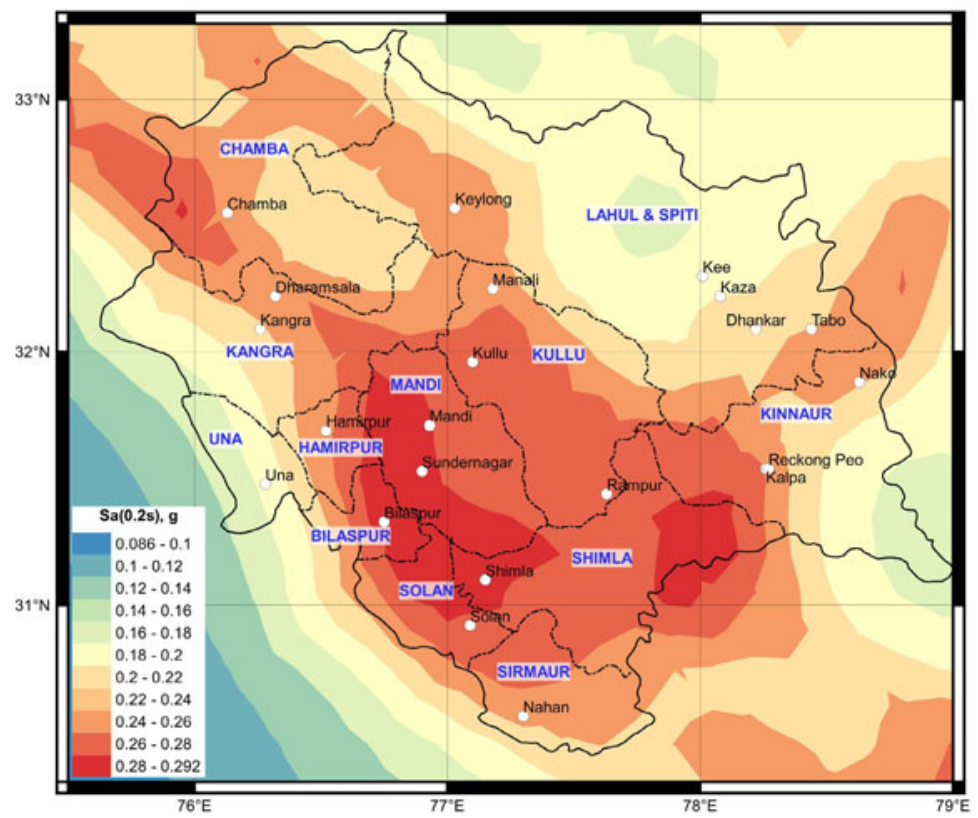

Fig. 14. $S a(0.2 s)$ contours with a return period of 475 years for $\mathrm{C}$ type sites.

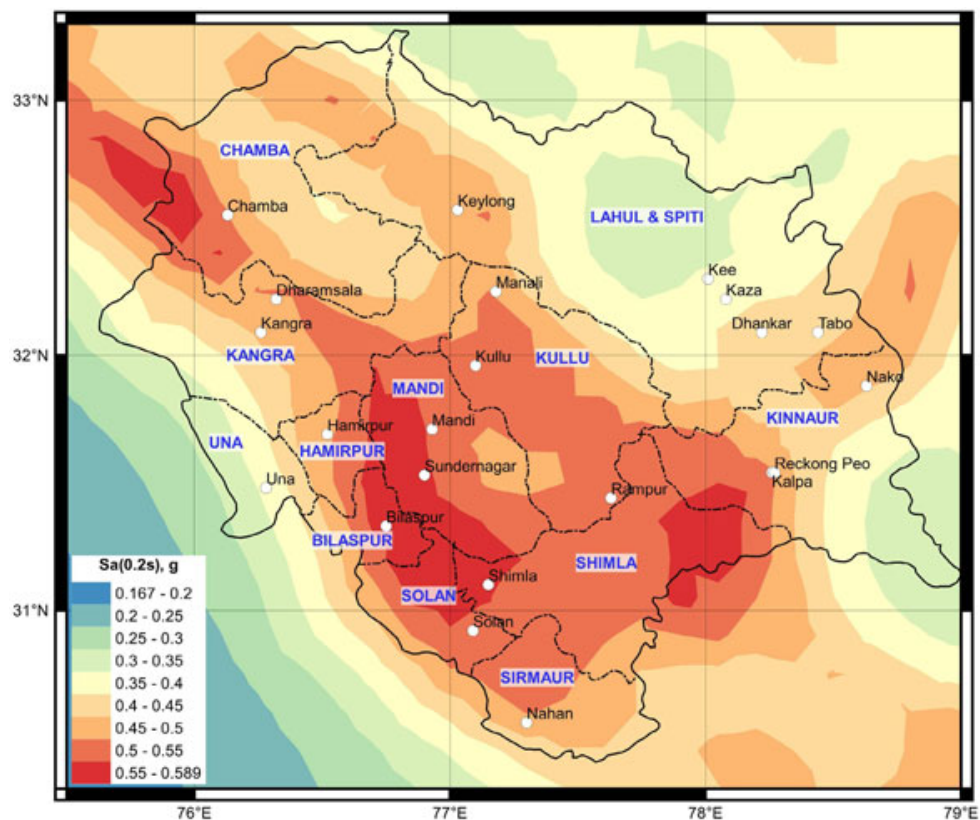

Fig. 15. $S a(0.2 s)$ contours with a return period of 2475 years for $\mathrm{C}$ type sites. 


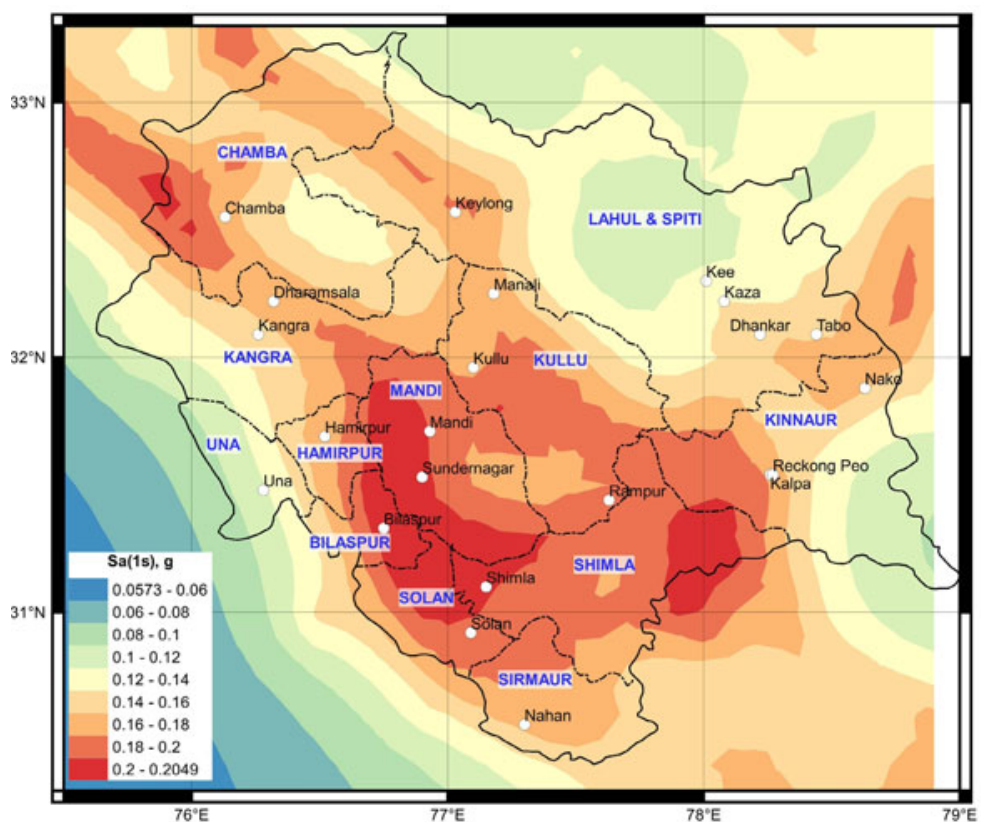

Fig. 16. $\mathrm{Sa}(1.0 \mathrm{~s})$ contours with a return period of 475 years for $\mathrm{C}$ type sites.

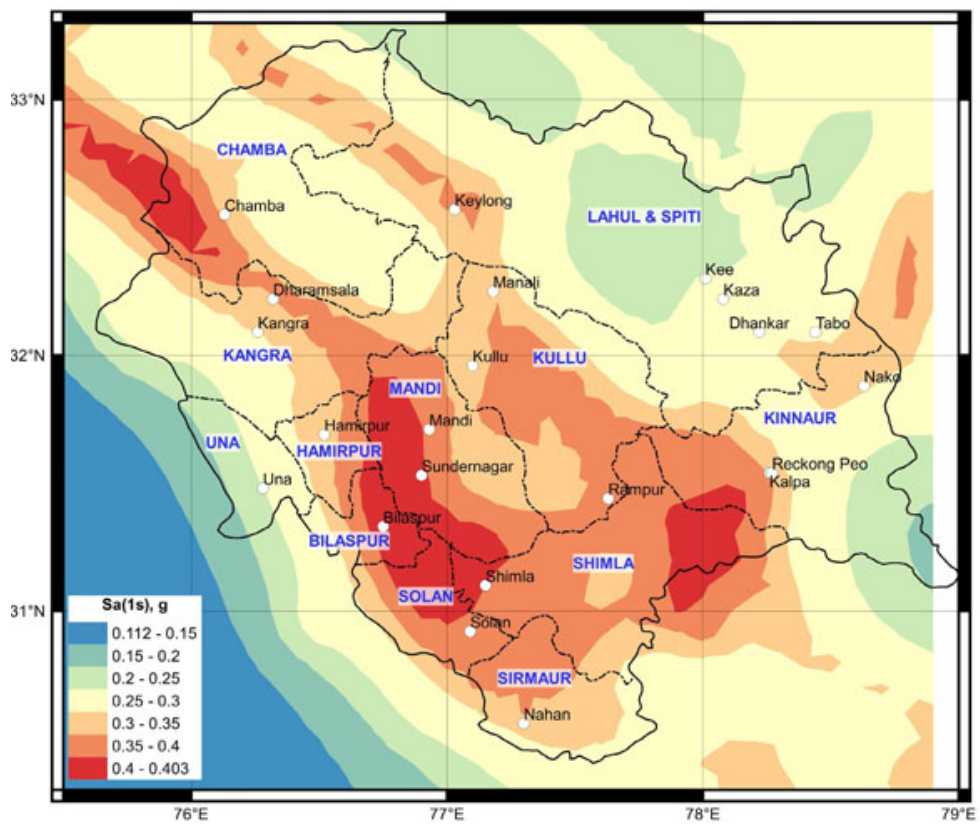

Fig. 17. $S a(1.0 s)$ contours with a return period of 2475 years for $\mathrm{C}$ type sites. 


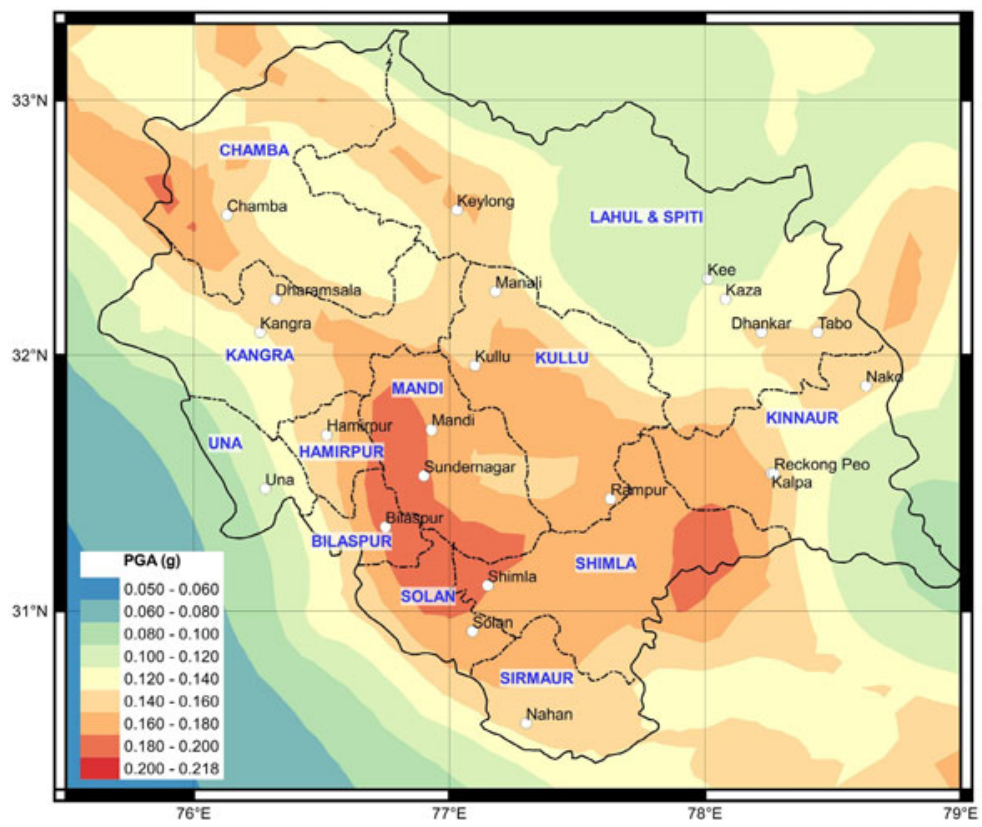

Fig. 18. PGA contours with a return period of 475 years for D type sites.

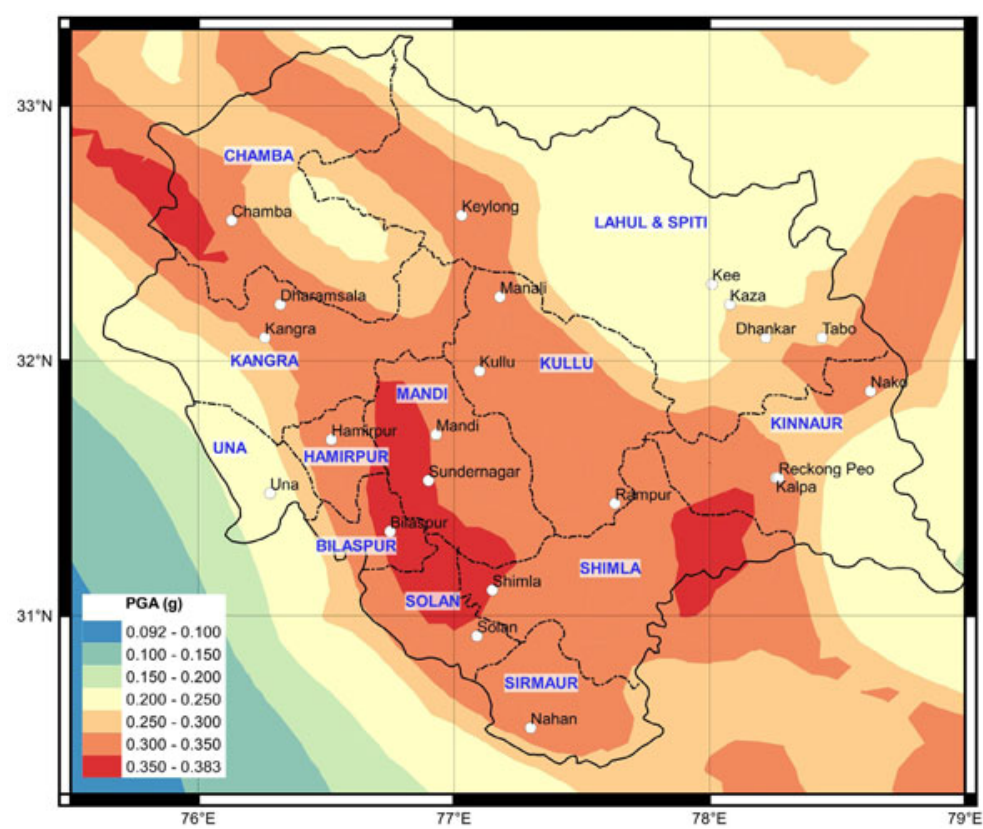

Fig. 19. PGA contours with a return period of 2475 years for D type sites. 


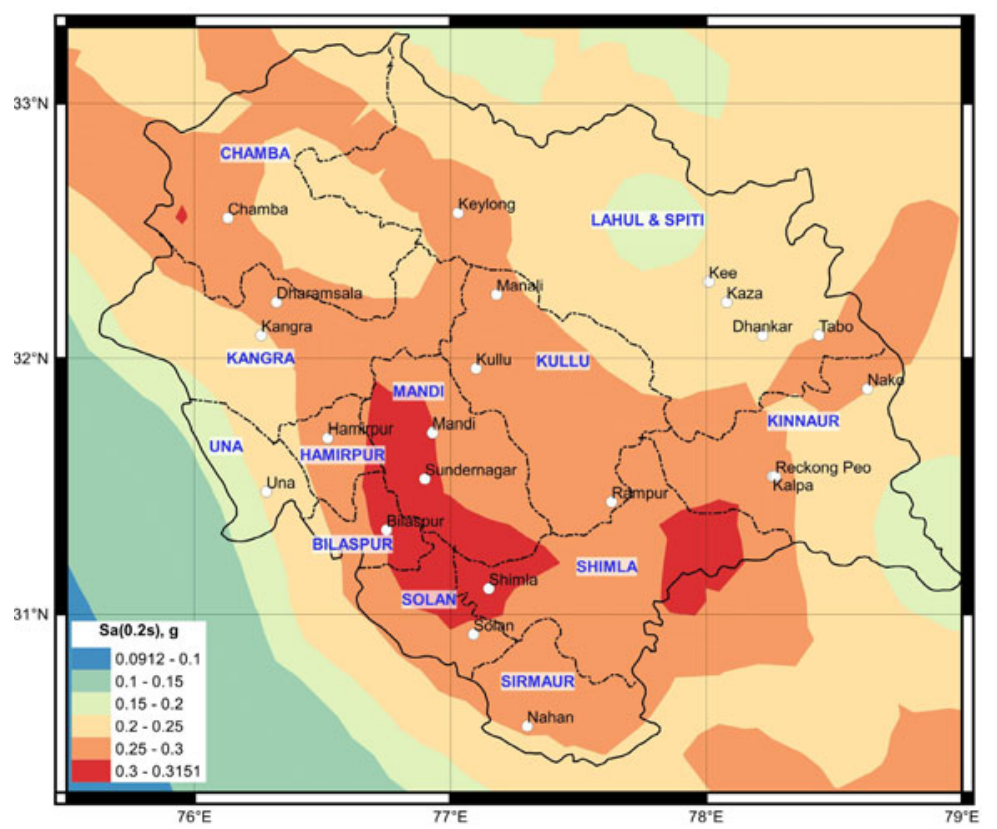

Fig. 20. $S a(0.2 s)$ contours with a return period of 475 years for D type sites.

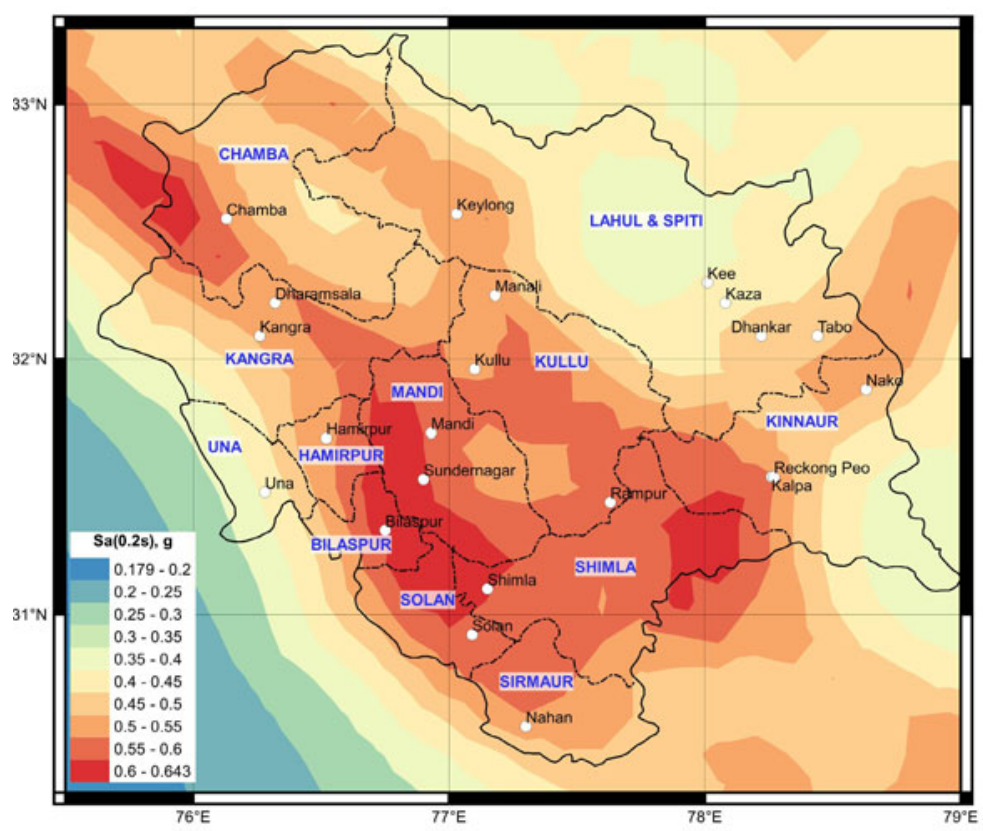

Fig. 21. $S a(0.2 s)$ contours with a return period of 2475 years for D type sites. 


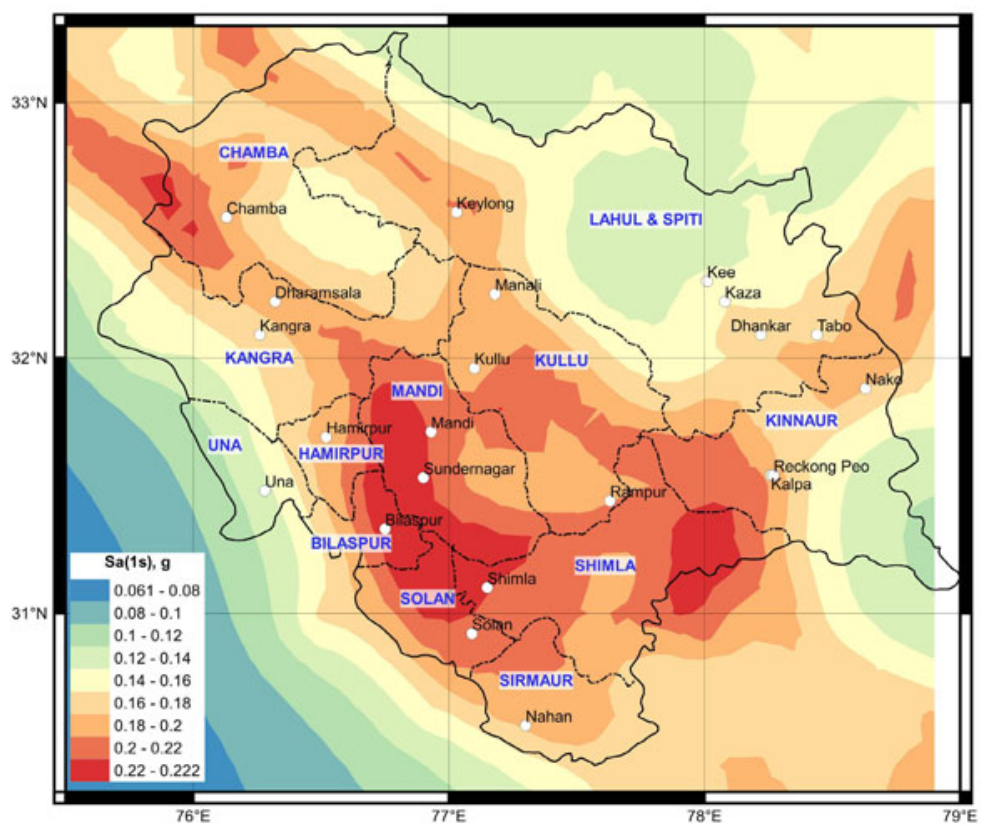

Fig. 22. $S a(1.0 s)$ contours with a return period of 475 years for D type sites.

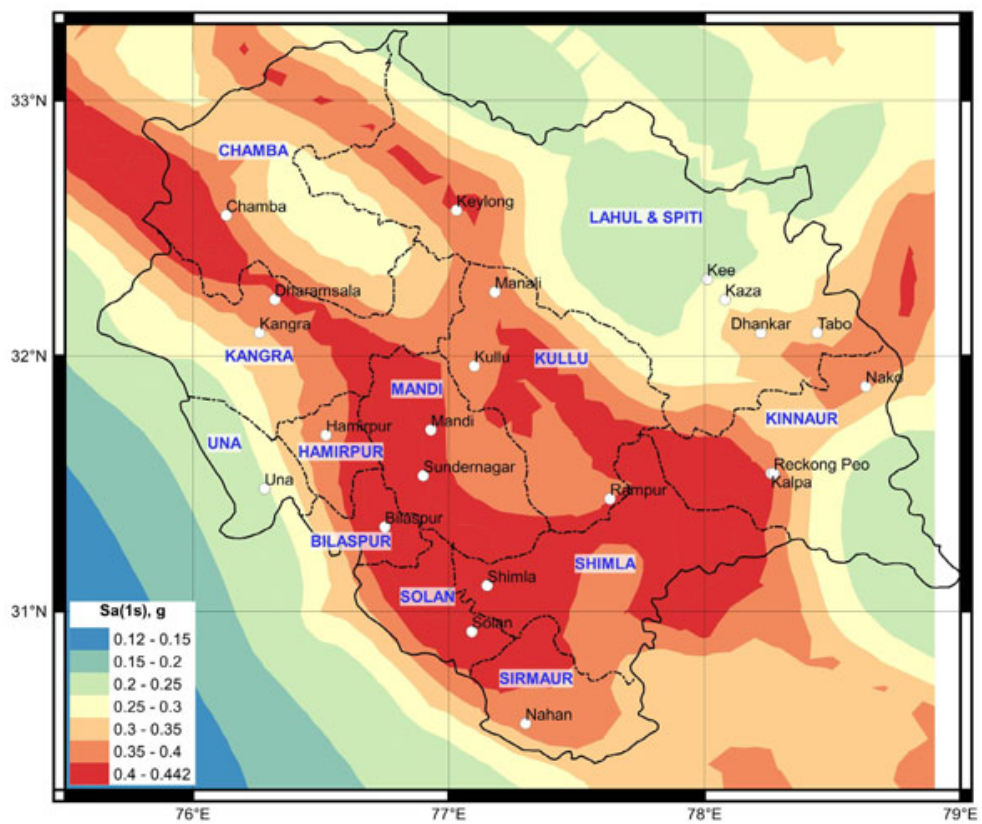

Fig. 23. $S a(1.0 s)$ contours with a return period of 2475 years for D type sites. 
Himalayan region are higher than the IG region, as expected. For example, the PGA values for a 475 year return period and class $C$ site, the hazard values at Hamirpur and Bilaspur, located in the Himalayan region, are greater than $0.14 \mathrm{~g}$ while it reduces to below $0.1 \mathrm{~g}$ in the Una city located in IG region less than $50 \mathrm{~km}$ away. It can be seen that the sparsely populated Lahaul $\&$ Spiti district shows lower hazard when compared to the densely populated cities in the lower Himalayan region, namely, Bilaspur, Shimla, Hamirpur, Chamba, Mandi, Solan, etc. This reiterates the need to evaluate the seismic risk and design sufficiency for the structures located in these regions. Similar trends are observed for the short and long period acceleration maps. Also, the difference in the PGA values for class C and D type can be observed in the range of 0.005-0.02 and 0.02-0.04 g for 475 and 2475 return periods, respectively. These differences are very similar for the $S a(0.2 \mathrm{~s})$ and $S a(1.0 \mathrm{~s})$ values and are in the range of 0.01-0.02 and 0.02-0.05 g for 475 and 2475 return periods, respectively. From the PGA values at class-D for 2475 year return period, the districts of Hamirpur, Bilaspur, Solan, Mandi, Shimla, Kullu, northern parts of Kangra, and the southern parts of Chamba exhibit nearly $35-65 \%$ more hazard levels than the districts of Una, Lahaul \& Spiti, northern Chamba, eastern Sirmaur, and a small region in the southern part of Kullu. Most importantly, the seismic hazard of the region surrounding Bilaspur, Chamba, and Kullu are found to be the highest within the study region and hazard of this region is higher than the previous studies (NDMA 2011, Patil et al. 2014).

The two return periods of 475 and 2475 years, for which hazard analysis has been carried out, are considered equivalent to the design basis earthquake (DBE) and the maximum considered earthquake (MCE). It would be interesting to compare the ratio MCE to DBE for the study region with the value of 2 suggested in the Indian codal provisions (IS: 1893 2002). On analyzing the PGA hazard values presented in this study, it was found that this scaling factor lies in the range of 1.67 to $2.18(\mu \pm \sigma=1.965 \pm 0.072)$ and 1.68 to $2.2(\mu \pm \sigma=1.98 \pm 0.075)$ for the class C- and D-site conditions, as shown in Fig. 24. The scaling factor for $S a(0.2 s)$ hazard values lie in the range of 1.77 to $2.19(\mu \pm \sigma=1.97 \pm 0.07)$ and 1.78 to $2.22(\mu \pm \sigma=1.99$ $\pm 0.072)$ for the class C- and D-site conditions. For $S a(1.0 s)$ hazard, these values are in the range of 1.69 to $2.12(\mu \pm \sigma=1.974 \pm 0.05)$ and 1.7 to 2.15 $(\mu \pm \sigma=1.99 \pm 0.053)$ for the class C and D-site conditions. Generally, these values were observed to be more than 2 in high hazard Himalayan regions and less than 2 in the IG regions (and within a small northern part of the Lahaul \& Spiti region). Thus, the period and site dependency of this scaling factor indicates that a uniform factor of 2 as per IS: 1893 (2002) may not appropriately scale the DBE event from MCE event for various regions. 
(a)

(b)
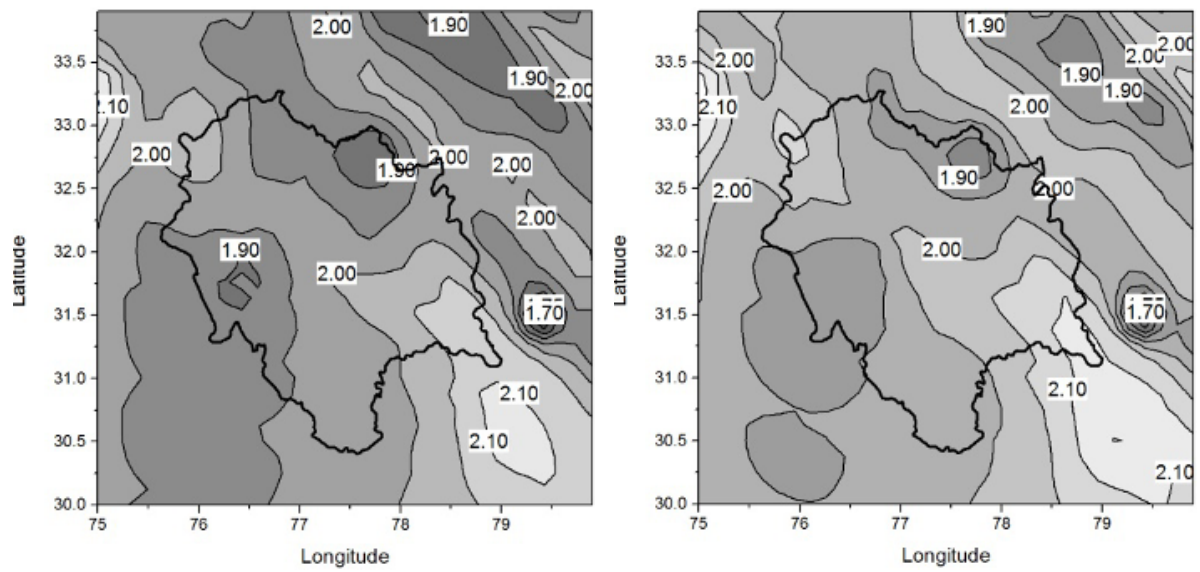

Fig. 24. Spatial variation of the MCE/DBE ratio of PGA values at class C (a) and class D (b) sites for 2475 year return period.

Similarly, it will be interesting to see the scaling of the hazard levels due to local site conditions. In this study region, it is observed that, on an average, the PGA values of the class D sites were 6.7 and $7.75 \%$ more than the class C sites for 475 and 2475 years return periods, respectively. For the $S a(0.2 s)$ and $S a(1.0 s)$, the increase in the value from class C to D was estimated as 6.5 and $5.7 \%$ for 475 years return period, while it was estimated to be 7.3 and $6.6 \%$ for 2475 years return period. Hence, the spectral acceleration coefficient used to account for the site effects in the Indian codal provisions, which is taken as 1 for scaling the PGA values for different soil types, is not appropriate.

Therefore, with the help of these contour plots, it is possible to construct a 5\% damped design response spectrum for class $\mathrm{C}$ and $\mathrm{D}$ sites located within this region for the return periods of 475 and 2475 years with the help of the two parameters, $S a(0.2 s)$ and $S a(1.0 s)$, using the methodology presented in IBC (2009).

\section{SUMMARY AND CONCLUSIONS}

The increase in population and development activities in the seismically vulnerable regions of Himachal Pradesh (HP) necessitates a robust estimation of the regional seismic hazard. This article presents state of the art hazard maps for this region with due consideration of the active seismicity, the regional geology and the local site effects. In this paper, the probabilistic seismic hazard analysis of this region has been carried out using the CornellMcGuire approach. An updated catalogue containing event records from 
25-2013 A.D. has been used to characterize the source level seismicity of all the probable 301 faults that are presently identified in and around this region. In the companion paper, regional site-specific ground motion relations have been developed for $\mathrm{C}$ and $\mathrm{D}$ type sites in the two geological regions of HP. These relations are used to compute the surface-level spectral hazard curves for the important cities in Himachal Pradesh. From these seismic hazard curves, the site-specific uniform hazard response spectra for twelve important cities have been presented for 475 and 2475 year return periods.

Also, the contour maps of three ground motion parameters, namely, peak ground acceleration (PGA), short period $S a(0.2 s)$ and long period $S a(1.0 s)$ spectral acceleration, are presented for this region. The comparison of the present estimates with the recent hazards estimates by NDMA (2011) and Patil et al. (2014) highlights the need to consider the local site variability in the hazard computation. Also, the regions surrounding the city of Bilaspur and Chamba were found to have much higher seismic hazard levels than previously reported. The estimated hazard values for these regions highlight that the zonal spectral values are underestimated in the Indian codal provisions. Hence, the maps developed in this study using a detailed probabilistic framework are more reliable and can be used for the seismic design of new structures in HP and also for assessing the seismic vulnerability of the existing structures. The obtained hazard curves combined with UHRS can be used to construct risk maps for HP.

In the present scenario with the limited amount of ground motion data available for this seismically active region, the estimates presented in this study should be the most practical estimates of surface hazard available for this region so far. However, the hazard estimates should become more reliable as more ground motion data become available in the future. Also, there is a need for estimating the seismic hazard of this region in terms of other ground motion parameters such as spectral velocity, spectral displacements, etc., which are necessary for the performance based design of structures.

\section{References}

Ambraseys, N., and R. Bilham (2000), A note on the Kangra $\mathrm{M}_{\mathrm{s}}=7.8$ earthquake of 4 April 1905, Curr. Sci. India 79, 1, 45-50.

Ambraseys, N., and D. Jackson (2003), A note on the early earthquakes in northern India and southern Tibet, Curr. Sci. India 84, 4, 570-582.

Bansal, B.K., and M. Verma (2013), Science and technology based earthquake risk reduction strategies: The Indian scenario, Acta Geophys. 61, 4, 808-821, DOI: 10.2478/s11600-013-0105-5. 
Bhatia, S.C., R.M. Kumar, and H.K. Gupta (1999), A probabilistic seismic hazard map of India and adjoining regions, Ann. Geophys. 42, 6, 1153-1164, DOI: 10.4401/ag-3777.

Bilham, R., S. Lodi, S. Hough, S. Bukhary, A.M. Khan, and S.F.A. Rafeeqi (2007), Seismic hazard in Karachi, Pakistan: Uncertain past, uncertain future, Seismol. Res. Lett. 78, 6, 601-631, DOI: 10.1785/gssrl.78.6.601.

Census (1991), Census of India 1991, Directorate of Census Operations, Himachal Pradesh, India.

Census (2011), Census of India 2011, Directorate of Census Operations, Himachal Pradesh, India.

Chandel, V.B.S., and K.K. Brar (2010), Seismicity and vulnerability in Himalayas: the case of Himachal Pradesh, India, Geomat. Nat. Hazard. Risk 1, 1, 6984, DOI: 10.1080/19475701003643441.

Cornell, C.A. (1968), Engineering seismic risk analysis, Bull. Seismol. Soc. Am. 58, 5, 1583-1606.

Department of Planning (2003), An overview of planning in Himachal Pradesh, Planning Department, State Government of Himachal Pradesh, India.

Der Kiureghian, A., and A.H.S. Ang (1977), A fault-rupture model for seismic risk analysis, Bull. Seismol. Soc. Am. 67, 4, 1173-1194.

Gardner, J.K., and L. Knopoff (1974), Is the sequence of earthquakes in southern California, with aftershocks removed, Poissonian? Bull. Seismol. Soc. Am. 64, 5, 1363-1367.

GSI (2000), Seismotectonic Atlas of India and its Environs, Geological Survey of India, Bangalore, India.

IBC (2009), International Building Code, International Code Council, International Seismological Centre (ISC), Thatcham, United Kingdom, on-line bulletin, available from http://www.isc.ac.uk.

IS:1893 (2002), Criteria for earthquake resistant design of structures: Part 1 - General provisions and buildings, Bureau of Indian Standards (BIS), New Delhi, India.

Iyengar, R.N., and S. Ghosh (2004), Microzonation of earthquake hazard in Greater Delhi area, Curr. Sci. India 87, 9, 1193-1202.

Iyengar, R.N., D. Sharma, and J.M. Siddiqui (1999), Earthquake history of India in medieval times, Indian J. History Sci. 34, 3.

Karan, P.P. (1966), Geographic regions of the Himalayas, Bull. Tibetology 3, 5-26.

Khattri, K.N., A.M. Rogers, D.M. Perkins, and S.T. Algermissen (1984), A seismic hazard map of India and adjacent areas, Tectonophysics 108, 1-2, 93-134, DOI: 10.1016/0040-1951(84)90156-2.

Kijko, A. (2004), Estimation of the maximum earthquake magnitude, $\mathrm{m}_{\max }$, Pure Appl. Geophys. 161, 8, 1655-1681, DOI: 10.1007/s00024-004-2531-4. 
Kijko, A., and G. Graham (1998), Parametric-historic procedure for probabilistic seismic hazard analysis: Part I: Estimation of maximum regional magnitude $\mathrm{M}_{\max }$, Pure Appl. Geophys. 152, 3, 413-442, DOI: 10.1007/ s000240050161.

Knopoff, L., and Y. Kagan (1977), Analysis of the theory of extremes as applied to earthquake problems, J. Geophys. Res. 82, 36, 5647-5657, DOI: 10.1029/ JB082i036p05647.

Kramer, S.L. (1996), Geotechnical Earthquake Engineering, Pearson Education, $672 \mathrm{pp}$.

Kumar, S., S.G. Wesnousky, T.K. Rockwell, D. Ragona, V.C. Thakur, and G.G. Seitz (2001), Earthquake reccurrence and rupture dynamics of Himalayan Frontal Thrust, India, Science 294, 5550, 2328-2331, DOI: 10.1126/ science. 1066195.

Lave, J., D. Yule, S. Sapkota, K. Basant, C. Madden, M. Attal, and R. Pandey (2005), Evidence for a great medieval earthquake ( 1100 A.D.) in the Central Himalayas, Nepal, Science 307, 5713, 1302-1305, DOI: 10.1126/ science. 1104804.

Mahajan, A.K., V.C. Thakur, M.L. Sharma, and M. Chauhan (2010), Probabilistic seismic hazard map of NW Himalaya and its adjoining area, India, Nat. Hazards 53, 3, 443-457, DOI: 10.1007/s11069-009-9439-3.

McGuire, R.K. (1976), FORTRAN computer program for seismic risk analysis, Open-file Report 76-67, U.S. Geological Survey, Denver, USA.

Milne, J. (1911), A catalogue of destructive earthquakes: A.D. 7 to A.D. 1899, British Association for the Advancement of Science, London, UK, $92 \mathrm{pp}$.

Montessus de Ballore, F. (1911), The seismic phenomena in British India and their connection with its geology, Mem. Geol. Surv. India 35, part 3 (reprint).

Muthuganeisan, P., and S.T.G. Raghukanth (2016), Site-specific probabilistic seismic hazard map of Himachal Pradesh, India. Part I. Site-specific ground motion relations, Acta Geophys. 64, 2, 336-361, DOI: 10.1515/acgeo-20160010

NDMA (2011), Development of probabilistic seismic hazard map of India, Tech. Report of the Working Committee of Experts (WCE), National Disaster Management Authority (NDMA), Govt. of India, New Delhi, India.

Oldham, T. (1883), Catalogue of Indian earthquakes from the earliest times to the end of 1869, Mem. Geol. Surv. India 19, 3, 1-53.

Parvez, I.A., F. Vaccari, and G.F. Panza (2003), A deterministic seismic hazard map of India and adjacent areas, Geophys. J. Int. 155, 2, 489-508, DOI: 10.1046/ j.1365-246X.2003.02052.x.

Patil, N.S., J. Das, A. Kumar, M.M. Rout, and R. Das (2014), Probabilistic seismic hazard assessment of Himachal Pradesh and adjoining regions, J. Earth Syst. Sci. 123, 1, 49-62, DOI: 10.1007/s12040-013-0378-8. 
PMD (2007), Seismic hazard analysis and zonation for Pakistan, Azad-Jammu and Kashmir, Pakistan Meteorological Department (PMD), Pakistan and NORSAR, Norway.

Prabhu, M., and S.T.G. Raghukanth (2014), Development of surface level probabilistic seismic hazard map of Himachal Pradesh. In: Proc. 9th Structural Engineers Convention (SEC 2014), 22-24 December 2014, Indian Institute of Technology, Delhi, India.

Quittmeyer, R.C., and K.H. Jacob (1979), Historical and modern seismicity of Pakistan, Afghanistan, northwestern India, and southeastern Iran, Bull. Seismol. Soc. Am. 69, 3, 773-823.

Raghukanth, S.T.G. (2011), Seismicity parameters for important urban agglomerations in India, Bull. Earthq. Eng. 9, 5, 1361-1386, DOI: 10.1007/s10518011-9265-3.

Stepp, J.C. (1972), Analysis of completeness of the earthquake sample in the Puget sound area and its effect on statistical estimates of earthquake hazard. In: Proc. 1st Int. Conf. on Microzonation, Seattle, USA, Vol. 2, 897-909.

Uhrhammer, R.A. (1986), Characteristics of northern and central California seismicity, Earthq. Notes 57, 1, 21.

USNRC (1997), USNRC Regulatory Guide 1.165: Identification and characterization of seismic sources and determination of safe shutdown earthquake ground motion, Unites States Nuclear Regulatory Commission, Washington D.C., USA.

Valdiya, K.S. (1976), Himalayan transverse faults and folds and their parallelism with subsurface structures of North Indian plains, Tectonophysics 32, 3-4, 353-386, DOI: 10.1016/0040-1951(76)90069-X.

Valdiya, K.S. (2002), Emergence and evolution of Himalaya: reconstructing history in the light of recent studies, Prog. Phys. Geog. 26, 3, 360-399, DOI: 10.1191/0309133302pp342ra.

Wells, D.L., and K.J. Coppersmith (1994), New empirical relationships among magnitude, rupture length, rupture width, rupture area, and surface displacement, Bull. Seismol. Soc. Am. 84, 4, 974-1002.

Received 16 September 2014 Received in revised form 27 March 2015 Accepted 10 April 2015 